\title{
In-Situ Metatranscriptomic Analyses Reveal the Metabolic Flexibility of the Thermophilic Anoxygenic Photosynthetic Bacterium Chloroflexus aggregans in a Hot Spring Cyanobacteria-Dominated Microbial Mat
}

\author{
Shigeru Kawai ${ }^{1,2, *}$, Joval N. Martinez ${ }^{1,3} \mathbb{D}^{\mathbb{D}}$, Mads Lichtenberg ${ }^{4} \mathbb{D}_{\text {, Erik Trampe }}^{4}$, Michael Kühl ${ }^{4} \mathbb{D}$, \\ Marcus Tank ${ }^{1,5}$, Shin Haruta ${ }^{1}$ (D) Arisa Nishihara ${ }^{1,6}$, Satoshi Hanada ${ }^{1}$ and Vera Thiel ${ }^{1,5, *}$
}

check for

updates

Citation: Kawai, S.; Martinez, J.N.; Lichtenberg, M.; Trampe, E.; Kühl, M.; Tank, M.; Haruta, S.; Nishihara, A.; Hanada, S.; Thiel, V. In-Situ Metatranscriptomic Analyses Reveal the Metabolic Flexibility of the Thermophilic Anoxygenic

Photosynthetic Bacterium Chloroflexus aggregans in a Hot Spring Cyanobacteria-Dominated Microbial Mat. Microorganisms 2021, 9, 652. https://doi.org/10.3390/ microorganisms 9030652

Academic Editor: Johannes F. Imhoff

Received: 28 January 2021

Accepted: 17 March 2021

Published: 21 March 2021

Publisher's Note: MDPI stays neutral with regard to jurisdictional claims in published maps and institutional affiliations.

Copyright: (C) 2021 by the authors Licensee MDPI, Basel, Switzerland. This article is an open access article distributed under the terms and conditions of the Creative Commons Attribution (CC BY) license (https:/ / creativecommons.org/licenses/by/ $4.0 /$ )
1 Department of Biological Sciences, Tokyo Metropolitan University, Hachioji, Tokyo 192-0397, Japan; j.martinez@usls.edu.ph (J.N.M.); mat19@dsmz.de (M.T.); sharuta@tmu.ac.jp (S.H.); arisa.nishihara@aist.go.jp (A.N.); satohana@tmu.ac.jp (S.H.)

2 Institute for Extra-cutting-edge Science and Technology Avant-garde Research (X-star), Japan Agency for Marine-Earth Science and Technology (JAMSTEC), Yokosuka, Kanagawa 237-0061, Japan

3 Department of Natural Sciences, College of Arts and Sciences, University of St. La Salle, Bacolod City, Negros Occidental 6100, Philippines

4 Department of Biology, Marine Biological Section, University of Copenhagen, Strandpromenaden 5, 3000 Helsingør, Denmark; mlichtenberg@sund.ku.dk (M.L.); etrampe@bio.ku.dk (E.T.); mkuhl@bio.ku.dk (M.K.)

5 DSMZ-German Culture Collection of Microorganisms and Cell Culture, GmbH Inhoffenstraße 7B, 38124 Braunschweig, Germany

6 Bioproduction Research Institute, National Institute of Advanced Industrial Science and Technology (AIST), Ibaraki 305-8566, Japan

* Correspondence: kawais@jamstec.go.jp (S.K.); Vera.Thiel@DSMZ.de (V.T.)

Abstract: Chloroflexus aggregans is a metabolically versatile, thermophilic, anoxygenic phototrophic member of the phylum Chloroflexota (formerly Chloroflexi), which can grow photoheterotrophically, photoautotrophically, chemoheterotrophically, and chemoautotrophically. In hot spring-associated microbial mats, C. aggregans co-exists with oxygenic cyanobacteria under dynamic micro-environmental conditions. To elucidate the predominant growth modes of C. aggregans, relative transcription levels of energy metabolism- and $\mathrm{CO}_{2}$ fixation-related genes were studied in Nakabusa Hot Springs microbial mats over a diel cycle and correlated with microscale in situ measurements of $\mathrm{O}_{2}$ and light. Metatranscriptomic analyses indicated two periods with different modes of energy metabolism of C. aggregans: (1) phototrophy around midday and (2) chemotrophy in the early morning hours. During midday, C. aggregans mainly employed photoheterotrophy when the microbial mats were hyperoxic (400-800 $\mu \mathrm{mol} \mathrm{L}-1 \mathrm{O}_{2}$ ). In the early morning hours, relative transcription peaks of genes encoding uptake hydrogenase, key enzymes for carbon fixation, respiratory complexes as well as enzymes for TCA cycle and acetate uptake suggest an aerobic chemomixotrophic lifestyle. This is the first in situ study of the versatile energy metabolism of C. aggregans based on gene transcription patterns. The results provide novel insights into the metabolic flexibility of these filamentous anoxygenic phototrophs that thrive under dynamic environmental conditions.

Keywords: filamentous anoxygenic phototroph; microbial mats; hot springs; metatranscriptomics; energy metabolism; carbon fixation

\section{Introduction}

Members of the genus Chloroflexus are thermophilic, filamentous anoxygenic phototrophs (FAPs) in the phylum Chloroflexota (formerly Chloroflexi). They are well known to have the ability to grow photoheterotrophically under anaerobic conditions and chemoheterotrophically under aerobic conditions in the laboratory [1-3]. While photoautotrophic 
growth in the laboratory has been observed only in a small number of isolated strains (e.g., Chloroflexus aurantiacus strain OK-70-fl [4-6], Chloroflexus sp. strain MS-G [7], and Chloroflexus aggregans strains NA9-6 [8,9] and ACA-12 [10]), the genes necessary for the 3-hydroxypropionate (3-OHP) bi-cycle, which is a carbon fixation pathway found only in members of the order Chloroflexales among bacteria, are present in all of the available Chloroflexus spp. genomes [11]. C. aggregans strains NA9-6 and ACA-12, which were isolated from Nakabusa Hot Springs (Nagano Prefecture, Japan), can grow photoautotrophically with hydrogen gas $\left(\mathrm{H}_{2}\right)$ [8] and sulfide [10] as the electron donors in pure culture, respectively. In addition to the long known phototrophic and chemoheterotrophic metabolism in Chloroflexus spp., chemoautotrophic growth has recently been shown in lab studies of C. aggregans strain NA9-6 [8]. In addition, fermentative growth has been shown in two isolates of C. aurantiacus, strains B3 and UZ [12].

Microbial mats in the slightly alkaline, sulfidic Nakabusa Hot Springs have been intensively studied with regard to their microbial diversity and functions [13-21]. At water temperatures of $63-70{ }^{\circ} \mathrm{C}$, olive-green microbial mats ("Chloroflexus mats") are dominated by C. aggregans $[14,15]$, and oxygenic cyanobacteria are not found. At lower temperatures of $45-62^{\circ} \mathrm{C}$, Chloroflexus spp. co-exist with cyanobacteria in dark blue-green microbial mats ("cyanobacterial mats"). These blue-green mats are stratified with a green upper layer dominated by the thermophilic cyanobacteria on top of an orange-colored layer that is frequently inhabited by C. aggregans [13].

In the anoxygenic, cyanobacteria-free phototrophic mats, C. aggregans is considered to be the main primary producer, using sulfide as the major electron source $[9,10,14-16]$. The metabolic repertoire of $C$. aggregans in the blue-green cyanobacterial mats has remained unstudied. In situ isotopic studies of similar cyanobacterial mats colonizing the effluent channels of Mushroom Spring and Octopus Spring in Yellowstone National Park (YNP; WY, U.S.) suggested that filamentous phototrophic Chloroflexota vary their carbon metabolisms over a diel cycle [22]. Based on transcriptomic data, Klatt et al. (2013) suggested photomixotrophic growth of a member of FAPs-i.e., Roseiflexus spp.-in Mushroom Spring during daytime and fermentative growth during the night [23]. Compared to the microbial mats in YNP, Nakabusa Hot Spring cyanobacterial mats are rich in C. aggregans, at a relative abundance of approximately $21-22 \%$ compared to only $1 \%$ in Mushroom Spring cyanobacterial mats $[13,24]$. This suggests an important ecological role and potential function of C. aggregans as a primary producer in the Nakabusa mats.

In this study, the in situ metabolic lifestyle of C. aggregans in the blue-green microbial mats of Nakabusa Hot Springs was analyzed by using a metatranscriptomic approach. Light is the main energy source during daytime, supporting photoautotrophic, photomixotrophic and photoheterotrophic growth of C. aggregans, while chemotrophic growth is prevalent during the afternoon and night. During the afternoon, under microaerobic low-light conditions chemoheterotrophic growth is based on $\mathrm{O}_{2}$ respiration, while at night fermentation is conducted under anaerobic conditions. Unexpectedly, chemoautotrophic growth using $\mathrm{O}_{2}$ as the terminal electron acceptor appeared to take place during early morning hours before sunrise, which suggests a vertical migration of $C$. aggregans cells to the microaerobic surface layers of the mats.

\section{Materials and Methods}

\subsection{Field Site and Sample Collection}

Blue-green cyanobacterial mat samples were collected from a small pool at $56{ }^{\circ} \mathrm{C}$ with slightly alkaline ( $\mathrm{pH} 8.5-8.9)$ and sulfidic $(46-138 \mu \mathrm{M})$ hot spring water $[18,25-27]$ at Nakabusa Hot Springs, Nagano Prefecture, Japan ( $36^{\circ} 23^{\prime} 33^{\prime \prime}$ N, $137^{\circ} 44^{\prime} 52^{\prime \prime}$ E) [20]. Microbial mat samples of approximately $3 \mathrm{~mm}$ thickness with two distinct vertical layers, a green top layer and an orange-colored bottom layer (Figure 1), were randomly collected in triplicate using a size 4 cork borer $(8 \mathrm{~mm}$ diameter) as previously described $[13,14]$. Samples were placed in $2 \mathrm{~mL}$ screw-cap tubes and snap-frozen in a dry-ice cooled, 70\% $(\mathrm{v} / \mathrm{v})$ ethanol bath on site. Samples were taken at 12 different time points over a diel 
cycle on 3 to 4 November, 2016 (19:00 and 23:00 on 3 November; 02:10, 05:00, 06:00, 07:00, 11:00, 15:00, 16:00, 17:00, 18:00, and 19:00 on 4 November) and were brought back to the laboratory on dry ice and stored in a $-80{ }^{\circ} \mathrm{C}$ freezer until further processing for metatranscriptomic analyses.

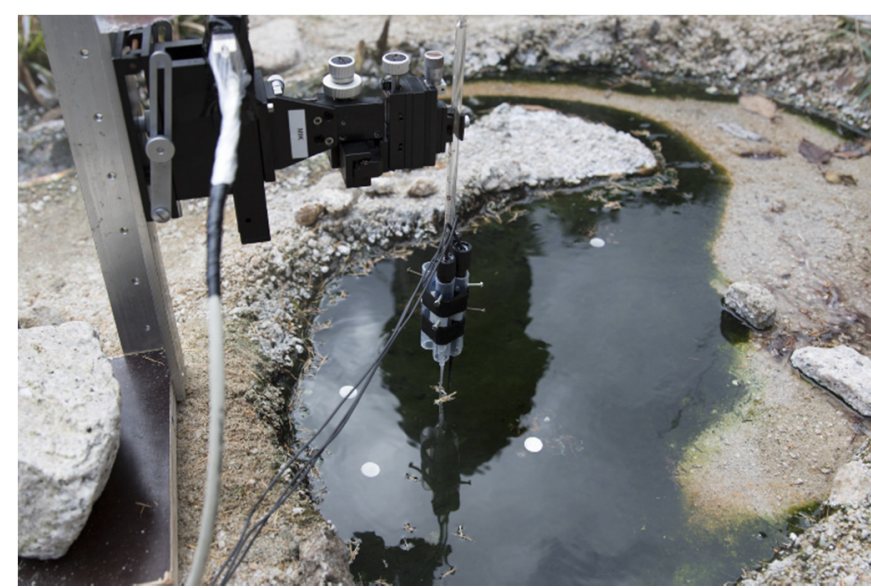

(a)

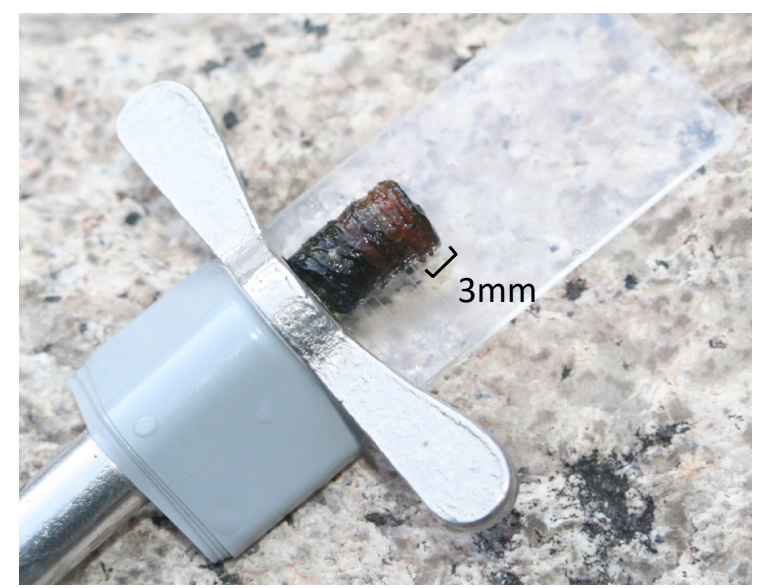

(b)

Figure 1. Photographs of the sampling site and cyanobacteria-dominated microbial mat. (a) The dark blue-green microbial mats developed at the "Stream Site" of Nakabusa Hot Springs, Japan [19]. (b) The microbial mat core samples collected at each time point were $8 \mathrm{~mm}$ in diameter and approx. $15 \mathrm{~mm}$ thick. The upper $3 \mathrm{~mm}$ of the core samples was used in this study.

\subsection{RNA Extraction}

RNA extraction from microbial mat samples was performed as previously described [18]. Briefly, 0.10-0.21 g wet weight samples were used for RNA extraction with an RNeasy PowerBiofilm Kit (Qiagen, Valencia, CA, USA) following the manufacturer's protocol. The RNA was treated with DNase I and eluted with RNase-free water. Purity and concentration of the RNA were determined using an RNA High Sensitivity (HS) assay with a Qubit 3.0 fluorometer (Life Technologies, Grand Island, NY, USA).

\subsection{RNA Sequencing}

Library preparation and sequencing of the RNA samples were conducted at DNALink Inc. (Seoul, Korea) as described previously [18]. RNA purity was determined by assaying $1 \mu \mathrm{L}$ of total RNA extract on a NanoDrop8000 spectrophotometer (Thermo Fisher Scientific, Waltham, MA, USA). Total RNA integrity was assessed by the RNA integrity number (RIN) using a 2100 Bioanalyzer (Agilent Technologies, Palo Alto, CA, USA). Total RNA sequencing libraries were prepared using a Truseq Stranded Total RNA Library prep kit and Ribo-Zero bacteria kit (both from Illumina, San Diego, CA, USA) according to the manufacturer's instructions.

First, $0.5 \mu \mathrm{g}$ of total RNA was subjected to ribosomal RNA depletion with Ribo-Zero bacteria reagent using biotinylated probes that selectively bind rRNA species. Following purification, the rRNA-depleted total RNA was fragmented into small pieces using divalent cations under elevated temperature. The cleaved RNA fragments were copied into firststrand cDNA using random primers and reverse transcriptase, followed by second-strand cDNA synthesis using DNA polymerase I and RNase $H$. A single 'A' base was then added to these cDNA fragments, and the adapter was ligated. The products were purified and enriched by polymerase chain reaction (PCR) to create the final cDNA library.

The quality of the amplified libraries was verified by capillary electrophoresis using the 2100 Bioanalyzer (Agilent Technologies, Palo Alto, CA, USA). After a quantitative (q)PCR using SYBR Green PCR Master Mix (Applied Biosystems, Carlsbad, CA, USA), index-tagged libraries were combined in equimolar amounts. RNA sequencing was 
performed using an Illumina NextSeq 500 system following the provided protocols for $2 \times 150$ sequencing.

\subsection{Sequence Data Analyses}

Raw RNA reads were pre-processed using FastQC [28]. Adapter sequence and lowquality reads were trimmed by Cutadapt ver. 1.12 [29]. Quality-checked reads were mapped against the complete genome of C. aggregans DSM 9485 (RefSeq acc. No. NC_011831.1) [2] with bowtie2 ver. 2.3.0 [30] with default settings allowing no mismatches. The reads were then aligned using the EDGE-pro algorithm [31] with the rRNA depletion option.

Transcriptomic analyses were conducted as described previously [18]. In short, read counts were normalized for each time point by the total number of reads retrieved for the target organism. The relative transcription of each gene during the cycle was then calculated and normalized against the mean of all of the reads at each time point for that particular gene over the diel cycle. This method allows comparison of the relative transcription abundance levels (rather than the absolute values) for each gene across the diel cycle.

\subsection{Statistical Analyses}

As described above, diel transcriptomic data in this study lacked replication. In the following Results and Discussion sections, the authors carefully interpreted and described and intentionally averaged the normalized transcriptional patterns of several genes related in a single pathway to recognize those gene transcription patterns as the pathway-level metabolic dynamics. However, some important genes function in an important enzyme reaction solely, the statistical analyses of each gene were performed to discuss the transcriptional changes over a diel cycle. For each gene in dual datasets, and for every possible pair-wise comparison of the 11 sets of adjacent samples (November 319:00-23:00; 3 November 23:00-4 November 2:10; 4 November 02:10-05:00, 05:00-06:00, 06:00-07:00, 07:00-11:00, 11:00-15:00, 15:00-16:00, 16:00-17:00, 17:00-18:00, 18:00-19:00), "exactTest" program in edgeR with dispersion set at 0.1 was used to determine the probability that the gene was differentially transcribed in a statistically significant manner [32,33].

\subsection{Microsensor Analyses}

The profiles of the $\mathrm{O}_{2}$ concentration as a function of depth in the microbial mat were measured in situ by using a Clark-type $\mathrm{O}_{2}$ microsensor (OX25; Unisense, Aarhus, Denmark) with a tip diameter of $<25 \mu \mathrm{m}$, low stirring sensitivity $(<1-2 \%)$ and fast response time $\left(\mathrm{t}_{90}<0.5 \mathrm{~s}\right)$. The $\mathrm{O}_{2}$ microsensor was mounted on a motorized micromanipulator (Unisense, Aarhus, Denmark) and connected to a PC-interfaced pA-meter (Unisense, Aarhus, Denmark), both of which were controlled by dedicated data acquisition, profiling, and positioning software (SensorTrace Pro, Unisense, Aarhus, Denmark). The micromanipulator was mounted on a metal stand placed next to the hot spring, allowing for vertical insertion of the microsensor tip into the microbial mat under natural flow, temperature and light conditions. The microsensor tip was carefully positioned at the mat surface (defined as $0 \mu \mathrm{m}$ ) by manual operation of the micromanipulator. Subsequently, $\mathrm{O}_{2}$ microprofiles were recorded automatically every $15 \mathrm{~min}$ for $24 \mathrm{~h}$ starting at 18:00 on 3 November 2016. In each profile, $\mathrm{O}_{2}$ measurements were made in $100 \mu \mathrm{m}$ increments from the water-phase and into the mat. One measurement was taken per depth and, for each measurement a $10 \mathrm{~s}$ wait period was applied, to ensure steady $\mathrm{O}_{2}$ signal, and the $\mathrm{O}_{2}$ signal was then recorded averaged over a $1 \mathrm{~s}$ period.

\subsection{Irradiance Measurements}

Downwelling solar photon irradiance $(400-700 \mathrm{~nm})$ at the water surface next to the mat was logged every $5 \mathrm{~min}$ throughout the $24 \mathrm{~h}$ diel sampling cycle with a calibrated light meter connected to a cosine-corrected photon irradiance sensor (ULM-500, MQS-B; Walz, Effeltrich, Germany). 


\section{Results}

\subsection{Irradiance and In Situ Oxygen Dynamics in the Microbial Mat}

The $\mathrm{O}_{2}$ concentration and penetration from the surface green layer to the deeper orange layer in the microbial mat varied dramatically with irradiance. The whole mat was anoxic during the night, and the $\mathrm{O}_{2}$ concentration started to increase at the mat surface at around 06:00, correlating with the time of sunrise and thus the onset of cyanobacterial oxygenic photosynthesis under diffuse light (Figures 1 and 2). However, $\mathrm{O}_{2}$ did not accumulate in deeper mat layers until later in the morning at around 09:00, when the microbial mats were exposed to direct sunlight as the sun rose over the surrounding mountains. Supersaturating $\mathrm{O}_{2}$ levels were observed in the uppermost mat layers at $~ 12: 00$ (noon) during the highest solar irradiance $\left(1531 \mu \mathrm{mol}\right.$ photons $\left.\mathrm{m}^{-2} \mathrm{~s}^{-1} ; 400-700 \mathrm{~nm}\right)$. The maximum $\mathrm{O}_{2}$ concentration at the microbial mat surface reached $>900 \mu \mathrm{mol} \mathrm{O}_{2} \mathrm{~L}^{-1}$ and with a maximal $\mathrm{O}_{2}$ penetration of $>2 \mathrm{~mm}$ depth under the highest irradiance between 10:00 and 14:00. Thus, there was sufficient $\mathrm{O}_{2}$ available for aerobic microbes in the upper $2 \mathrm{~mm}$ of the mat during this period of the day. In the afternoon, after 14:00, $\mathrm{O}_{2}$ concentration started to decrease gradually (from approx. $500 \mu \mathrm{mol} \mathrm{O}_{2} \mathrm{~L}^{-1}$ ) and no $\mathrm{O}_{2}$ was detected at a depth of 1-2 mm shortly after 15:00. The upper layer remained oxic $\left(100-200 \mu \mathrm{mol} \mathrm{O}_{2} \mathrm{~L}^{-1}\right)$ until 16:00. At this time, the microbial mats experienced a substantial decrease in solar irradiance (see Figures 3-8 and S1-S5) as the sun set behind the mountains. However, low levels of diffuse sunlight $\left(<100 \mu \mathrm{mol}\right.$ photons $\left.\mathrm{m}^{-2} \mathrm{~s}^{-1} ; 400-700 \mathrm{~nm}\right)$ hit the microbial mats until complete darkness was observed at 17:00. Anoxic conditions started to become established in the lower parts of the microbial mats $\sim 2 \mathrm{~h}$ before sunset, potentially enabling anaerobic and microaerophilic metabolism under low-light conditions during this time interval.

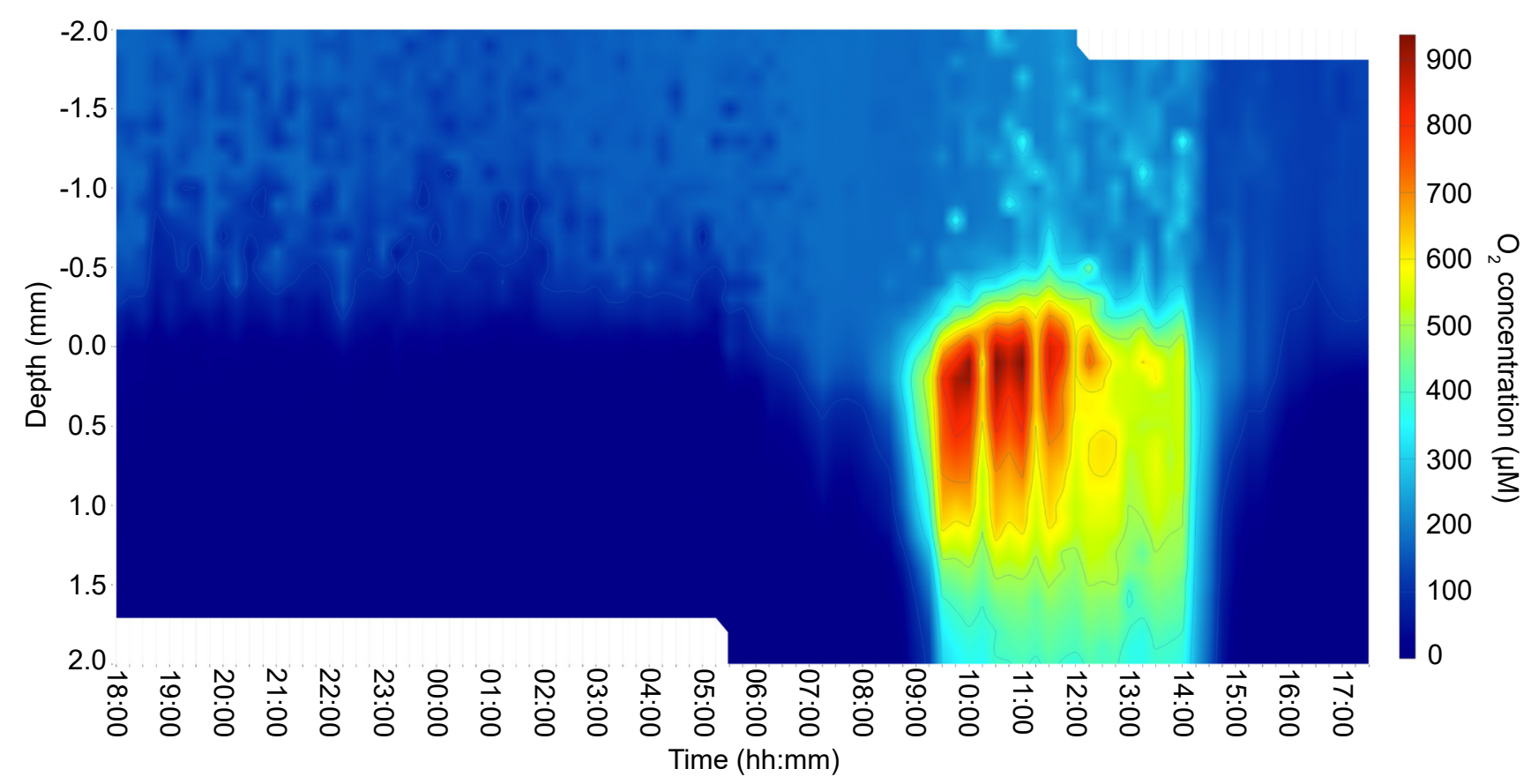

Figure 2. A heat map of the vertical $\mathrm{O}_{2}$ concentration profiles in the cyanobacteria-dominated microbial mat of Nakabusa Hot Springs as measured over a diel cycle. The $\mathrm{O}_{2}$ concentration $\left(\mu \mathrm{mol} \mathrm{L}{ }^{-1}\right)$ was measured as a function of depth in the microbial mat at 15-min intervals for $24 \mathrm{~h}$ from 18:00 on 3 November to 18:00 on 4 November. The mat surface is indicated by $0 \mathrm{~mm}$. Positive depth values indicate the depth below the mat surface, and negative values indicate the depth above the mat surface, i.e., the distance into the overlying water column of the hot spring.

\subsection{Transcriptome Profiles and Differentially Transcribed Genes}

Approx. 0.26-5.23 million reads of transcripts were assigned to the C. aggregans genome throughout the day (Table S1). Among 3848 CDSs contained in the genome of C. aggregans DSM9485 ${ }^{\mathrm{T}}$, the number of genes in which more than 10 transcripts were de- 
tected in all timepoints was 2542-3506 genes. Statistical significance of transcription level changes of each gene was determined using the $p$-value $(p<0.05)$ based on the "exactTest" function in edgeR [32]. Thousands of genes were differentially transcribed during the period from 19:00 on 3 November to 15:00 on 4 November indicating a versatile and changing transcriptional activity between the different time points. During 15:00-16:00 as well as 17:00-19:00, the numbers of significantly differentially transcribed genes were considerably lower (less than $10 \%$ of all CDSs), indicating transcriptional activity of C. aggregans during this period was relatively stable compared with former $20 \mathrm{~h}$ of the day. Those times were taken together as 'afternoon' and 'evening', respectively, in which both transcriptional activity as well as environmental conditions are expected to be rather similar. Overall the statistics support the changes in relative transcriptional levels and activity of C. aggregans to be significant. Detailed information on the differential transcription of the genes discussed is given in Tables S2 and S3.

\subsection{Transcription of Photosynthesis-Related Genes}

Chloroflexus aggregans contains a type 2 photosynthetic reaction center complex (RC) and light-harvesting chlorosomes; the main photosynthetic pigments are bacteriochlorophylls (BChls) $c$ and $a$ [2]. Transcripts of pufLMC genes (Cagg_1639-1640 and Cagg_2631) encoding RC proteins in C. aggregans showed significant nocturnal patterns and were most abundant in the evening and at night (Figure 3). Similarly, nocturnal transcriptional patterns of chlorosome proteins encoded by csmAMNOPY genes (Cagg_1222, Cagg_1209, Cagg_1208, Cagg_2486, Cagg_1206, and Cagg_1296) were detected (Figure 3).

BChl synthesis-related bch genes in C. aggregans in the mats showed inconsistent transcription patterns, with the highest relative transcription levels either under oxic conditions during the daytime (11:00) and/or under microoxic conditions in the afternoon (15:00; Table S4). In total, four different groups of transcription patterns could be distinguished for $b c h$ genes. Group I ( $b c h H-I I I, b c h I-I$ and II, $b c h Y, b c h Z, a c s F, b c h L, b c h B, b c h N, b c h M)$ showed highest relative transcription during the daytime (midday, 11:00). Group II (bchH-I and II, $b c h J, b c h F, b c h X, b c h C)$ showed maximal values in the afternoon around 15:00, with more or less pronounced lows at 11:00. The two other groups showed highest relative transcription levels under anaerobic conditions. Four genes $(b c h G, b c h K, b c h U$, and $b c h P)$ showed peaks at 18:00. $b c h D$ and $b c h I-I I I$ had maximal relative transcription in the early morning at 05:00.

Paralogs with different patterns were present for the genes encoding Mg-chelatase, i.e., $b c h H$ (three paralogs; Cagg_0239, 0575, 1286) and bchI (three paralogs; Cagg_1192, 2319, 3123). In all three cases, the paralogs showed differences in absolute read abundance as well as different temporal peaks in relative transcription over the day (Table S4).

Two different genes encoding for $\mathrm{Mg}$-protoporphyrin monomethylester cyclase are present in C. aggregans. AcsF and BchE both catalyze the synthesis of divinylprotochlorophyllide from Mg-protoporphyrin IX 13-monomethyl ester (one of the intermediates in the BChl synthesis pathway) under aerobic and anaerobic conditions, respectively [34-36]. acsF (Cagg_1285) was transcribed throughout the diel cycle with relative transcription levels about four times higher during day, when the mat was (super)oxic than under anoxic conditions at night (Figure 3). In contrast to acsF, the bchE (Cagg_0316) showed significantly lower relative transcription levels (only 1/32 of the diel average) under high-light/high- $\mathrm{O}_{2}$ conditions in the mat and higher transcription levels during the night as well as during low-light transition times in the morning and afternoon (Figure 3). 


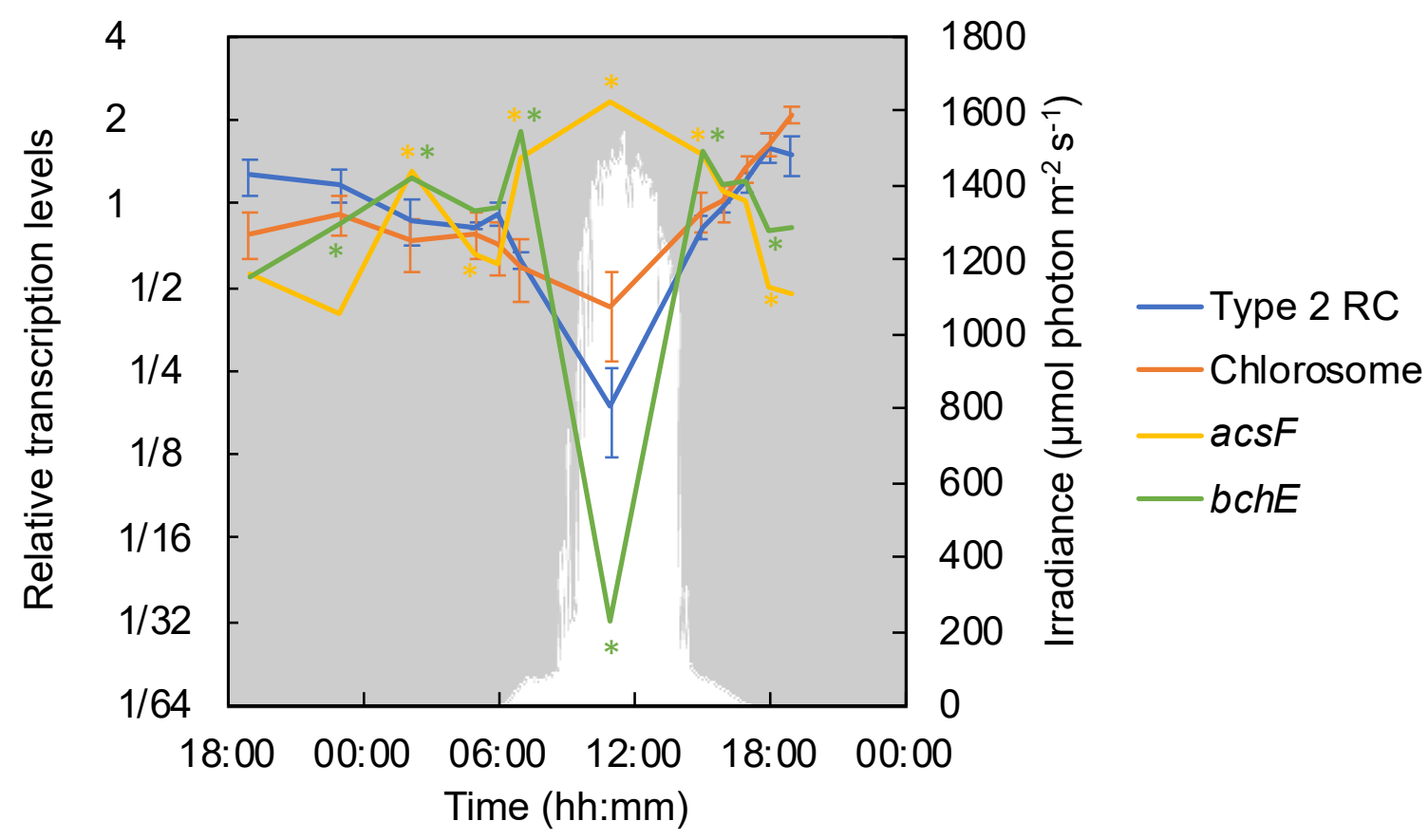

Figure 3. Relative transcription levels of genes encoding photosynthetic reaction center and chlorosome proteins, as well as genes involved in bacteriochlorophyll biosynthesis. Mean values of genes encoding the type 2 reaction center (RC) (pufLMC: Cagg_1639-1640 and Cagg_2631) and chlorosome proteins (csmAMNOPY: Cagg_1222, Cagg_1209, Cagg_1208, Cagg_2486, Cagg_1206, and Cagg_1296) are represented by a blue line and an orange line, respectively, with standard deviations. The values of Mg-protoporphyrin IX monomethyl ester aerobic cyclase (acsF, Cagg_1285, yellow line) and anaerobic cyclase (bchE, Cagg_0316, green line) are shown. The downwelling photon irradiance (photosynthetically active radiation [PAR]; $400-700 \mathrm{~nm}$ ) is indicated in white. The asterisk indicates the transcription of a particular gene corresponding to the color in a timepoint differed significantly $(p<0.05)$ from that in the previous timepoint.

\subsection{Phototrophic and Respiratory Electron Transport}

Electron transport chains are involved in both phototrophic and chemotrophic (respiratory) metabolism. Chloroflexus spp. contain paralogs of some of the major enzyme complexes involved in the electron transport chain, namely, NADH:menaquinone oxidoreductase (Complex I) [11,37,38] alternative complex III (ACIII) [39-41] and the soluble electron carrier auracyanin [42-45] in their genomes. Single-copy genes are present encoding succinate dehydrogenase (Complex II) [46,47] and F-type ATP synthase (Complex V) [48].

The respiratory complex I carries out the transfer of electrons between soluble cytoplasmic electron carriers and membrane-bound electron carriers coupled to proton translocation generating a transmembrane proton motive force. C. aggregans DSM9485 ${ }^{\mathrm{T}}$ contains two sets of genes encoding Complex I (NADH:menaquinone oxidoreductase, $n u$ ): one (Cagg_1620-1631) represents a cluster comprising 12 genes with an additional nuoM (2-M complex) inserted between the original nuoM1 and nuoN genes (nuоABCDHJKLMMN, 3); the second is a complete cluster comprising 14 genes (Cagg_1036-1049). The additional proton-pumping subunit NuoM has been speculated to lead to a higher stoichiometry of protons translocated per $2 \mathrm{e}^{-}$reaction cycle [49]. Both sets of $n u o$ genes were transcribed and showed the highest relative transcription during the daytime (Figure S1). The 14-gene set showed a transcriptional peak at 11:00 and the 12-gene peak came slightly later (in the afternoon at 15:00-16:00). Both nuo gene sets showed a small transcription peak in the early morning at 05:00.

Alternative complex III (ACIII) transfers electrons from menaquinol to water-soluble proteins such as auracyanin, the blue copper electron carrier protein found in Chloroflexus spp. [44]. Two types of ACIII have been reported in Chloroflexus spp.: Cp, which is thought to be involved in cyclic phototrophic electron transport, and $\mathrm{Cr}$, which is predicted to 
be related to the reduction of oxygen in respiratory electron transport $[11,23,39]$. In the present study, clear diel patterns as well as differences between the two sets of genes were observed. The genes encoding Cp showed high relative transcription levels all day with the highest level at 11:00 and a significant decrease in the afternoon as the sunlight vanished. The $\mathrm{Cr}$ genes were not highly transcribed under the daytime high $\mathrm{O}_{2}$ conditions in the mat, but they significantly increased and exhibited maximal relative transcription levels in the microoxic low-light afternoon hours at 15:00 and 16:00 (Figure 4). Genes for both Cp and $\mathrm{Cr}$ were highly transcribed in the early morning at 5:00.

Two homologs encoding the soluble electron carrier protein auracyanin, aurA and aur $B$, are present in the genome of C. aggregans. The transcriptional profile of aur $A$ in C. aggregans in the cyanobacterial mats in the present investigation showed patterns similar to those of $\mathrm{Cr}$ and other genes involved in the respiratory electron transport chain, with one significant peak in the early morning at 05:00 and another under microoxic and anaerobic conditions in the afternoon and evening (15:00 until 18:00; Figure 4). In contrast, aurB was significantly higher transcribed during a high-light period (11:00) as well as at 05:00.

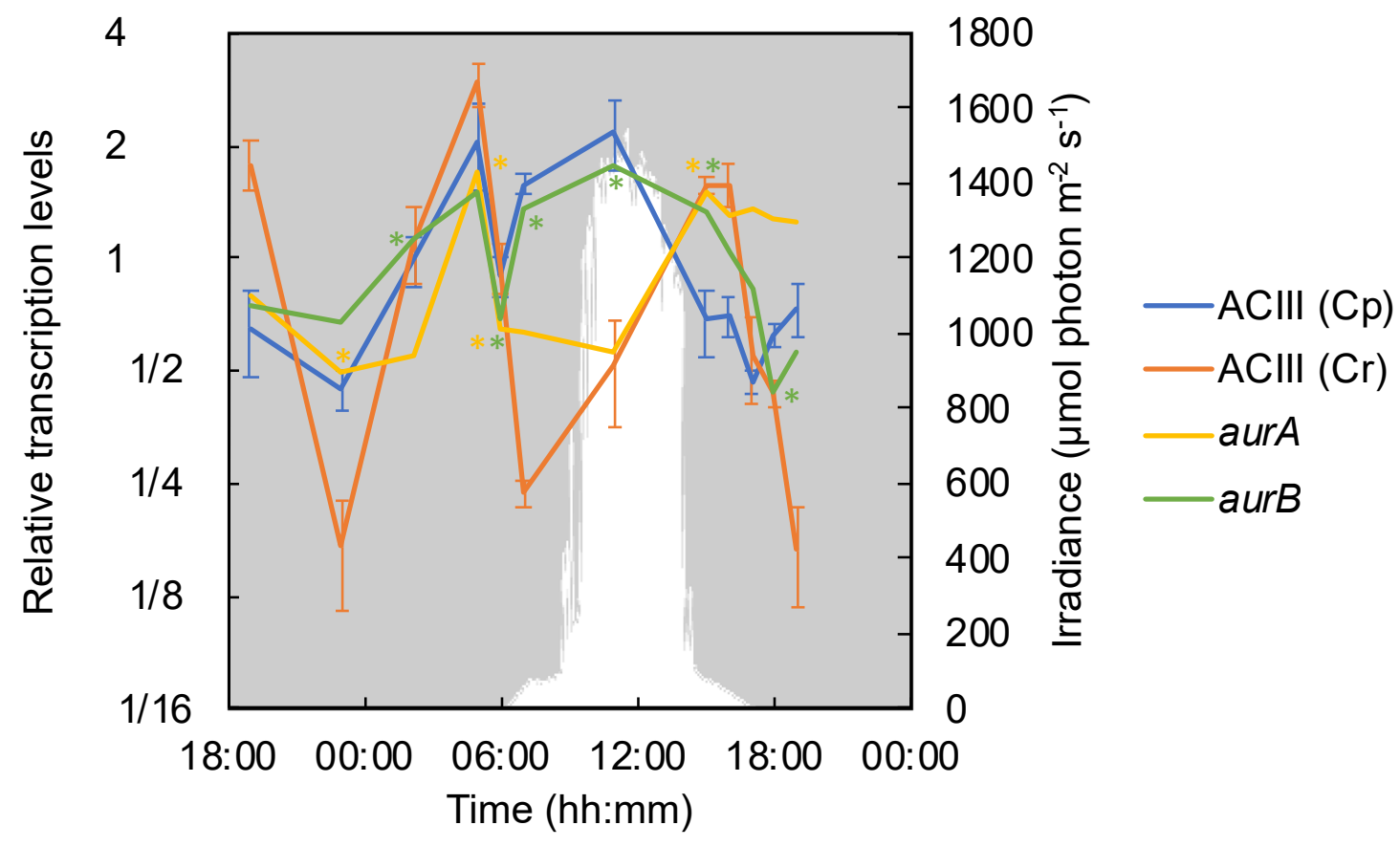

Figure 4. Relative transcriptional levels for alternative complex III (ACIII) and auracyanin. The mean values of ACIII (Cp, Cagg_3382-3383, and 3385-3387) for phototrophic electron transfer and ACIII (Cr, Cagg_1523-1527) for chemotrophic electron transfer are represented by a blue line and an orange line, respectively, with standard deviations. The values of aur $A$ and aurB (Cagg_0327 and 1833) encoding auracyanin are respectively displayed as yellow (aurA) and green (aurB) lines. The downwelling photon irradiance (PAR; 400-700 nm) is indicated in white. The asterisk indicates the transcription of a particular gene corresponding to the color in a timepoint differed significantly from that in the previous timepoint.

Respiratory Complex IV-i.e., the cytochrome $c$ oxidase complex-plays a key role in the reduction of $\mathrm{O}_{2}$ to $\mathrm{H}_{2} \mathrm{O}$ in the respiratory electron transport chain. The oxygen profiles over the diel cycle indicated high $\mathrm{O}_{2}$ concentrations in the mats during the daytime (Figure 2). In the laboratory, Chloroflexus spp. can grow chemoheterotrophically using respiration under aerobic dark conditions. In Chloroflexus spp., the cytochrome c oxidase (COX, or Complex IV; EC 1.9.3.1) genes are clustered with the Cr operon (Cagg_15191522). Similar to $\mathrm{Cr}$, the average relative transcription levels of these COX genes reached their highest values in the early morning at 05:00 and in the afternoon at 15:00 and 16:00 (Figure 5).

Chloroflexus aggregans possesses a type-B succinate dehydrogenase (Complex II) which comprises one polypeptide and two hemes for a transmembrane cytochrome $b(s d h C)$ in 
addition to a flavoprotein subunit $(s d h A)$ and iron-sulfur subunit $(s d h B)$ [50,51]. Complex II encoded by sdhCAB (Cagg_1576-1578) is involved in electron transport as well as in the TCA cycle and the 3-OHP bi-cycle. They showed significant high relative transcription levels in the morning at 05:00 and during the daytime, and were significantly low throughout the night (Figure 5).

F-type ATP synthase is involved in the production of ATP based on the proton motive force obtained by phototrophic as well as respiratory electron chain activity. The ATP-synthase consists of two parts: $\mathrm{F}^{1}$, which is a catalytic part, and $\mathrm{F}^{0}$, which is a transmembrane proton channel part [48]; C. aggregans DSM9485 $5^{\mathrm{T}}$ contains a complete gene set for both parts in the genome [11]. Similar to Complex I-1, II, and ACIII Cp, the relative transcription of ATP-synthase showed a diurnal pattern with two peaks, one at 05:00 and the other at 11:00 (Figure 5).

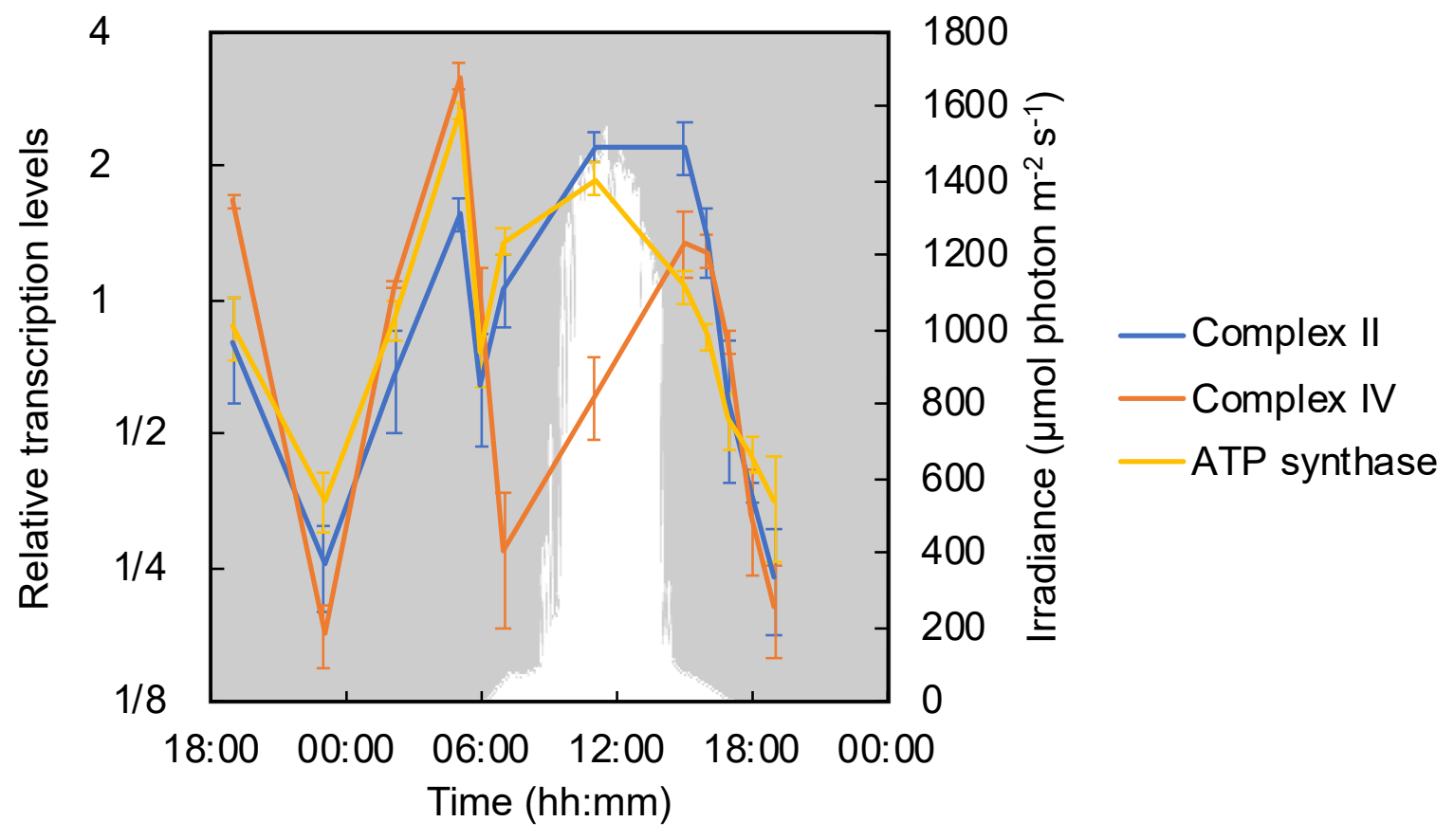

Figure 5. Relative transcription levels of respiratory complex II, IV and ATP synthase. The mean values of the relative transcripts of respiratory complex II (Cagg_1576-1578, blue line), complex IV (Cagg_1519-1522, orange line) and ATP synthase (Cagg_0984-991, yellow line) are shown with standard deviations. The downwelling photon irradiance (PAR; $400-700 \mathrm{~nm}$ ) is indicated in white.

\subsection{3-Hydroxypropionate Bi-Cycle and Anaplerotic Carbon Fixation}

Chloroflexus spp. contain all genes for the 3-hydroxypropionate (3-OHP) bi-cycle, a carbon fixation pathway found only in members of filamentous phototrophic Chloroflexota [11,52-57]. The number of transcripts per million (TPM) for genes encoding key enzymes of the 3-OHP bi-cycle, i.e., malonyl-CoA reductase (Cagg_1256) and 3hydroxypropionyl-CoA synthase (Cagg_3394) [23], were considerably higher than the average of all genes and appeared relatively stable over the diel cycle (Table S5). Although transcription was detected at all times, the relative transcripts of the two key enzyme genes on average peaked at 15:00. The second highest peak of 3-OHP bi-cycle key enzyme genes was detected at 05:00 before sunrise, and again at 07:00. Under the oxic, high-light conditions, at 11:00, the relative transcriptional levels of the genes encoding key enzymes of 3-OHP bi-cycle were the lowest (Figure 6).

Filamentous anoxygenic phototrophs also contain anaplerotic pathways for incorporating inorganic carbon, such as phosphoenolpyruvate carboxylase (ppc, Cagg_0399), which catalyzes the unidirectional production of oxaloacetate from phosphoenolpyru- 
vate $[11,58,59]$. Transcripts of $p p c$ were abundant during the daytime under aerobic, highlight conditions (Figure 6).

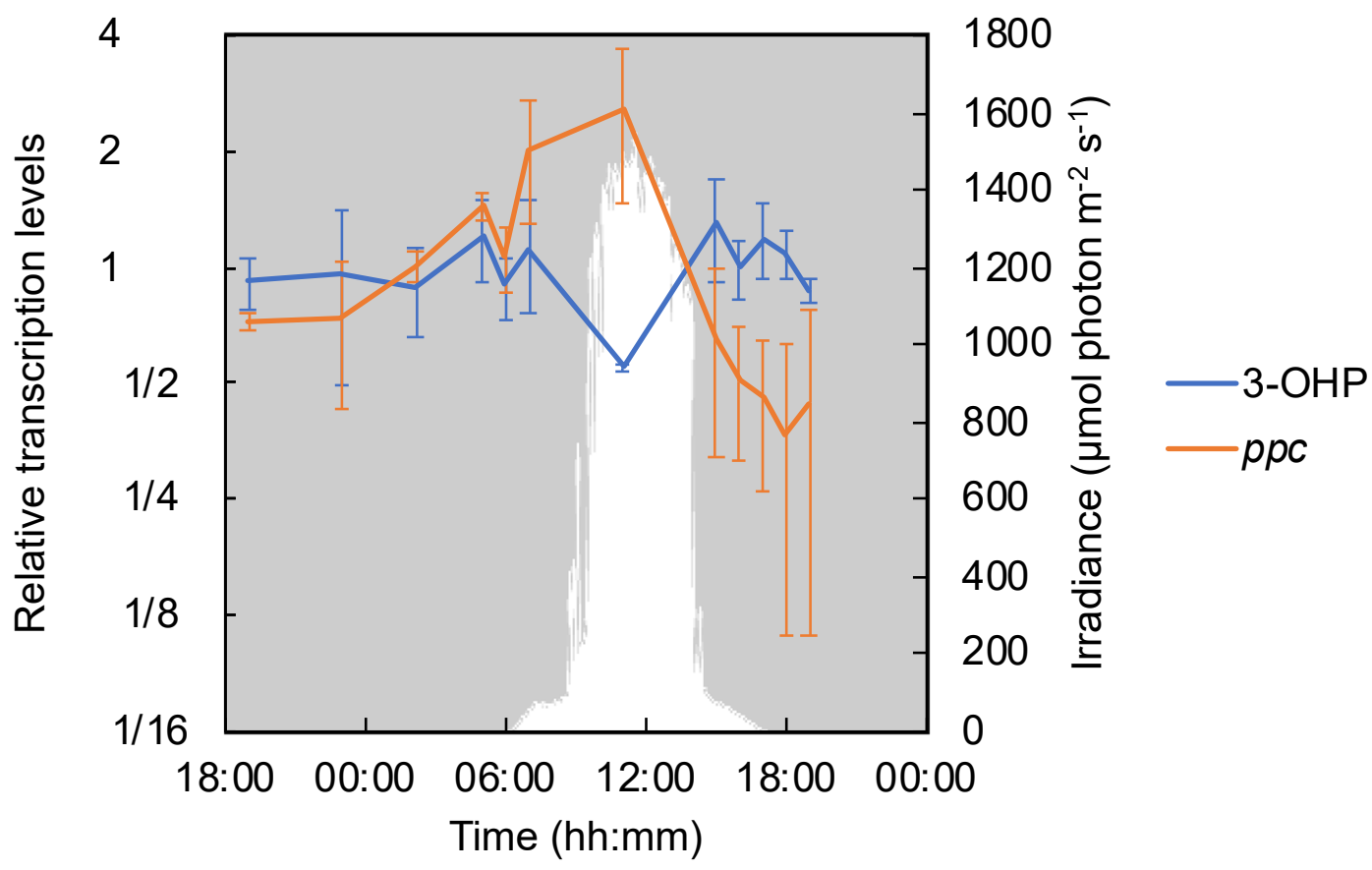

Figure 6. Relative transcription levels of genes encoding key enzymes of the 3-OHP bi-cycle and related enzymes of the anaplerotic pathway in cyanobacterial mats. The mean values of the relative transcription levels of key 3-OHP enzymes, i.e., malonyl-CoA reductase (Cagg_1256) and propionyl-CoA synthase (Cagg_3394), plus that of phosphoenolpyruvate carboxylase (ppc, Cagg_0058 and 0399) are represented by a blue line and an orange line, respectively, with standard deviations. The downwelling photon irradiance (PAR; $400-700 \mathrm{~nm}$ ) is indicated in white.

\subsection{Electron Donors: Hydrogenase, Sulfide: Quinone Reductase and CO-Dehydrogenase}

Recent studies demonstrated that $C$. aggregans has the capability to use sulfide as well as $\mathrm{H}_{2}$ as an electron donor for photoautotrophic growth [9,10]. Genome analyses have suggested that carbon monoxide can also serve as a potential electron donor [11]. The correlation between the relative transcriptions of genes encoding hydrogenases, sulfide:quinone reductase and carbon monoxide dehydrogenase and the genes encoding key enzymes in the 3-OHP bi-cycle was analyzed in order to predict autotrophic metabolism.

C. aggregans contains two $\mathrm{Ni}-\mathrm{Fe}$ hydrogenases: a bidirectional hydrogenase (Cagg_2476-2480) and an uptake hydrogenase (hyd, Cagg_0470-0471)-that can provide electrons for autotrophic growth $[60,61]$. Relative transcription levels of hyd genes encoding the uptake hydrogenase significantly increased in the afternoon (at 15:00) shortly after the direct solar illumination of the mats ended around 14:00 and anaerobic conditions were established in the deeper layers of the mat, as well as in the early morning at 05:00 (Figures 2 and 7). The relative transcription levels for genes encoding the bidirectional hydrogenase (Cagg_2476-2480) peaked a little later in the evening after sunset (17:00, $\mathrm{PAR}=0$ ), stayed high throughout the night, and then decreased during the day. Nickel transporter genes showed the same high relative transcription pattern as the hyd genes, with peaks in the early morning and the afternoon (Figure 7).

Chloroflexus spp. contain type-II sulfide:quinone oxidoreductase (SQR), which oxidizes sulfide to elemental sulfur, but lack the $d s r$ genes, which encode genes involved in the oxidation of elemental sulfur to sulfate as observed in green and purple sulfur bacteria [11,62], and also lack the sox system, which oxidizes elemental sulfur and thiosulfate to sulfate and is widespread in chemoautotrophic sulfur oxidizers [63]. In the present study, a significant increase of relative transcription levels with the highest peak of $s q r$ was detected in the afternoon, at 15:00 (Figure 7) under microaerobic to anaerobic low-light conditions in the mat. 
As a third possibility, based on the presence of genes encoding carbon monoxide dehydrogenase (coxGSML, Cagg_0971-0974) in the genome, the capability of Chloroflexus spp. to utilize $\mathrm{CO}$ as an electron donor and/or carbon source during aerobic or microaerobic growth has been discussed [11]. In the present investigation, the coxGSML genes were significantly higher transcribed during high-light conditions around noon (Figure 7) as well as during the afternoon as the mats turned anoxic. A significant increase in the relative transcription of cox genes was seen under anaerobic, low-light conditions in the morning at 07:00 together with a spike in the relative transcription for genes encoding key enzymes of the 3-OHP bi-cycle. The relative transcription of hydrogenase and sqr genes were clearly and significantly decreased at that time.

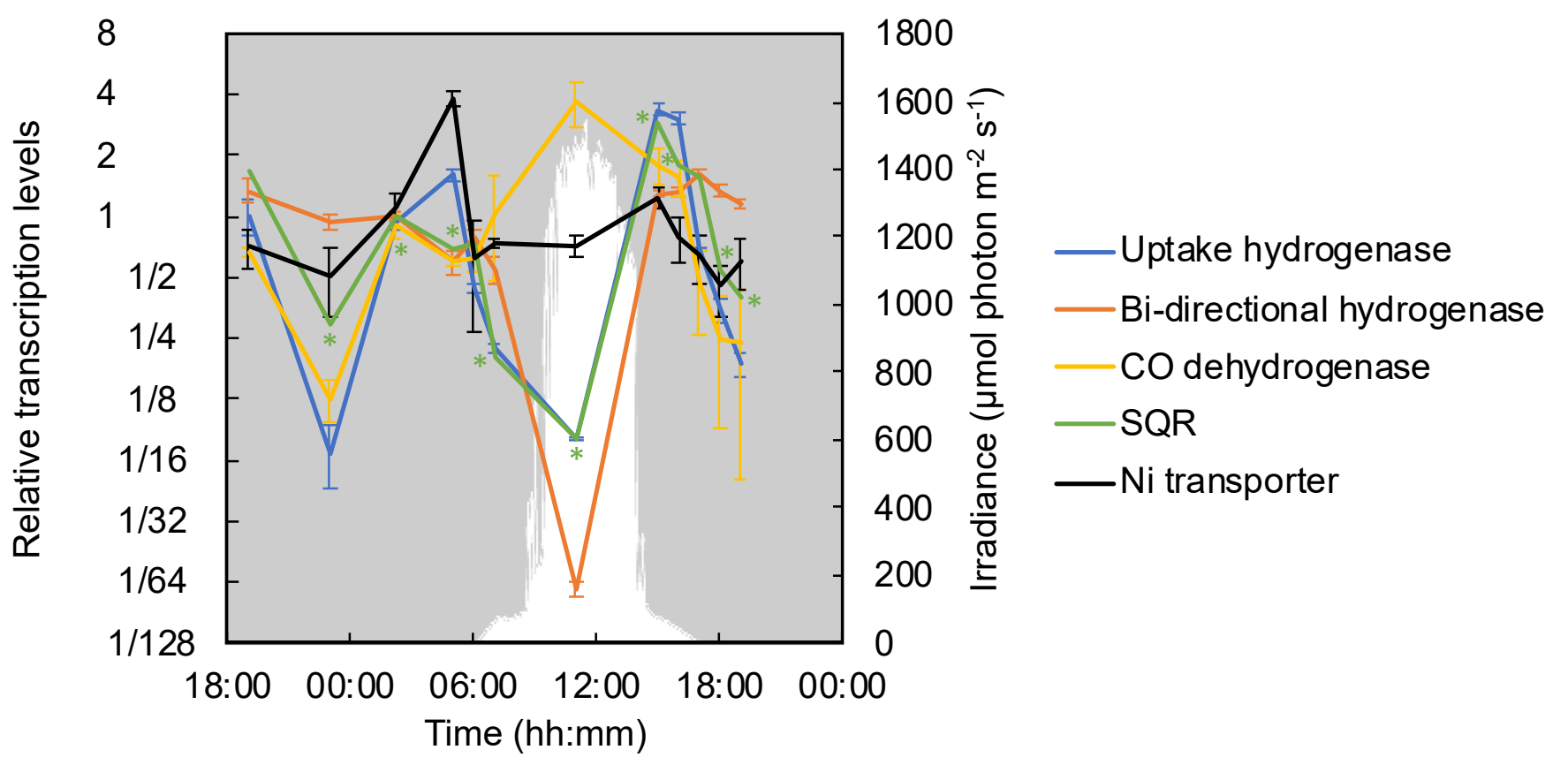

Figure 7. Relative transcription levels of genes encoding hydrogenases, sulfide:quinone oxidoreductase and nickel transporter in cyanobacterial mats. The mean values of the relative transcription levels for type-I uptake Ni-Fe hydrogenase genes hydAB (Cagg_0470-0471, blue line), bi-directional Ni-Fe hydrogenase genes homologous to frhA, frhG, hoxU, nuoF and hoxE (Cagg_2476-2480, orange line), carbon monoxide (CO) dehydrogenase genes coxGSML (Cagg_0971-0974, gray line), and nickel transporter genes (Cagg_1273-1276, light blue line) are shown with standard deviations. The relative transcription levels of the type-II sulfide:quinone oxidoreductase gene (sqr, Cagg_0045) are represented by the black line. The downwelling photon irradiance (PAR; 400-700 nm) is indicated in white. The asterisk indicates the transcription of a particular gene corresponding to the color in a timepoint differed significantly from that in the previous timepoint.

\subsection{Carbohydrate Metabolism and the TCA Cycle}

Chloroflexus aggregans contains the gene set for the pentose phosphate pathway (PP), including the key enzymes for the oxidative phase involved in anabolic pathways, i.e., glucose-6-phosphate dehydrogenase (Cagg_3190) and 6-phosphogluconate dehydrogenase (Cagg_3189) [23]. Herein, the transcription levels of the two key enzyme genes showed a significant diurnal pattern with the highest relative transcription under high-light conditions (11:00) and an additional peak at 05:00 (Figure 8). Similar to the genes of the oxidative pentose phosphate pathway, high relative transcription levels were also detected at those times for other genes that are indicative of active metabolism and growth, such as DNA gyrase, DNA polymerase, and RNA polymerase (Figure S2).

Because many of the enzymes involved in glycolysis are bi-directional and similarly used in gluconeogenesis, the transcriptional patterns of genes related to glycolysis were analyzed by focusing on the unidirectional enzyme, 6-phosphofructokinase (Cagg_3643), which irreversibly catalyzes the reaction from fructose-1,6-phosphate to 
fructose-6-bisphosphate to predict chemoheterotrophic growth and catabolism. In C. aggregans, two genes are annotated as genes encoding 6-phosphofructokinase (Cagg_3643 and Cagg_2702). These two genes differ considerably in length, with Cagg_2702 encoding a protein identified as a member of the 6PF1K_euk superfamily, the eukaryotic type of the 6phosphofructokinase, which is almost twice as long as the 'bacterial' 6-phosphofructokinase version, represented by Cagg_3643 (747 aa vs. 356 aa) [64]. Homologs of the Cagg_2702 gene are present in many Chloroflexota genomes as identified by a BLAST search, but are not generally present in many other bacteria. The two genes differed in the relative transcription levels and patterns. Cagg_2702 showed the same diel transcription pattern as other genes involved in glycolysis, with its highest relative transcription during high-light conditions at 11:00 (see Table S5). In contrast, Cagg_3643 showed the highest relative transcription under anaerobic conditions in the evening and the lowest transcription levels during superoxic, high-light conditions (Figure 8), but it showed considerably higher absolute transcription levels (TPM average of 1312.12 vs. 9.28 for Cagg_2702). Because Cagg_3643 represents the 'bacterial' type of the enzyme (with higher similarity to the 6-phosphofructokinase in E. coli) and since it showed higher absolute transcription levels, it is hypothesized that it represents the unidirectional gene involved in the oxidative activity of glycolysis in C. aggregans.
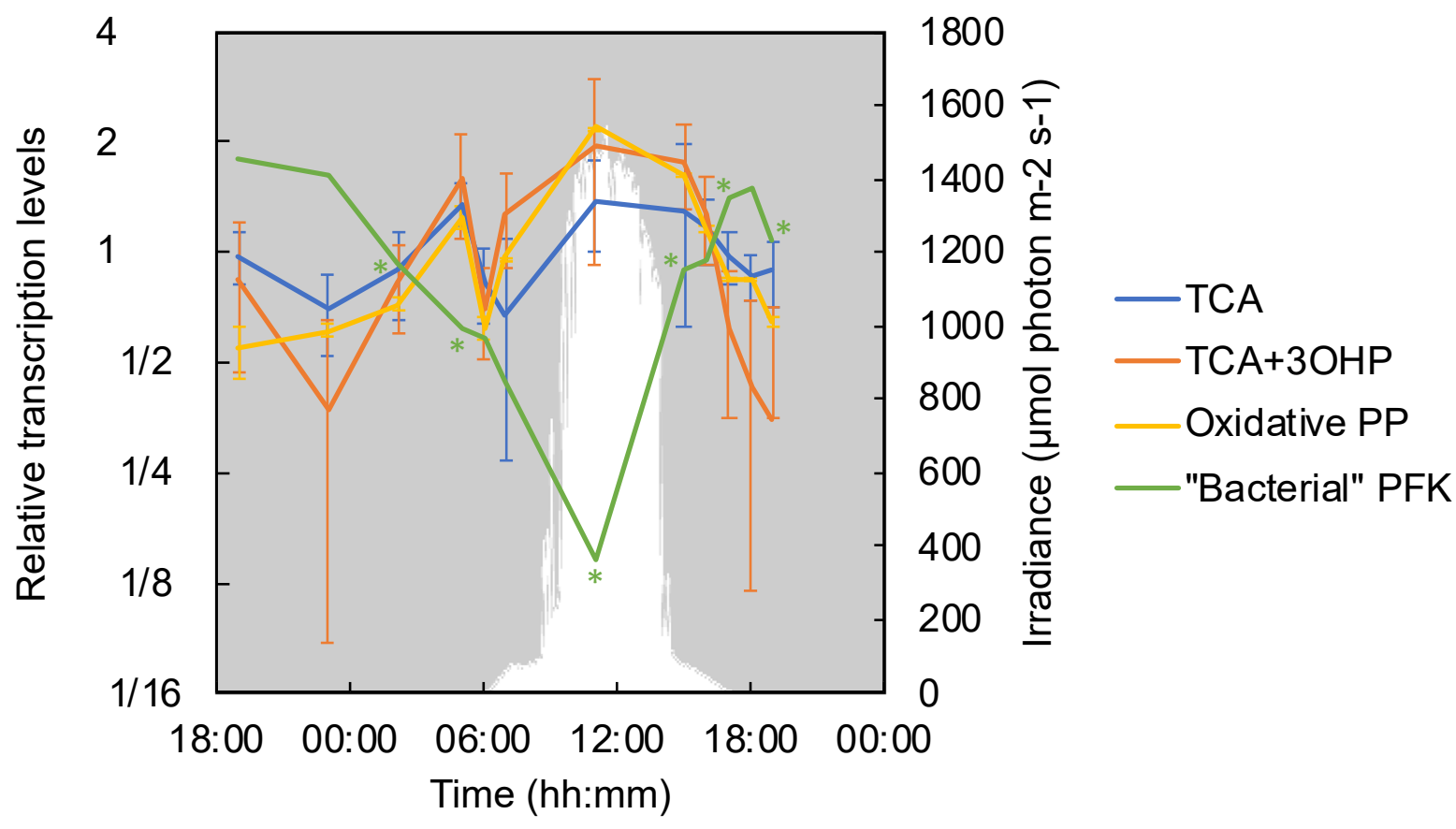

Figure 8. Relative transcription levels of genes for carbohydrate metabolism. The mean values of the relative transcriptional levels for the TCA cycle (Cagg_3738, 3721, 2500, and 2290) and common enzymes of the TCA cycle and the 3-OHP bi-cycle that is labeled as 'TCA+3-OHP' (Cagg_2086, 2819, and 1576-1578) are represented by a blue line and an orange line with standard deviations. The mean values of the relative transcripts of genes encoding key enzymes of the pentose phosphate pathway (Oxidative PP)—i.e., glucose-6-phosphate dehydrogenase (Cagg_3190) and 6-phosphogluconate dehydrogenase (Cagg_3189)_ are represented by the yellow line with standard deviation. The values of the relative transcription levels are displayed for genes encoding the 'bacterial' type of the 6-phosphofructokinase that is labeled as "Bacterial” PFK (Cagg_3643, green line). The downwelling photon irradiance (PAR; $400-700 \mathrm{~nm}$ ) is indicated in white. The asterisk indicates the transcription of a particular gene corresponding to the color in a timepoint differed significantly from that in the previous timepoint.

The oxidative TCA cycle is important for oxygen-respiring heterotrophic organisms, and all Chloroflexus species are known to have the ability to grow chemoheterotrophically [1-3] with oxygen as the terminal electron acceptor. Some of the reactions involved in the TCA cycle-e.g., the conversions from succinyl-CoA to malate-are also part of the 3-OHP bicycle [65]. Therefore, the transcriptional patterns of succinyl-CoA synthase (Cagg_2086 and 
Cagg_2819), succinate dehydrogenase (Cagg_1576-1578), and fumarate lyase (Cagg_2500) are labeled as 'TCA+3-OHP' and the genes that are exclusively present in the TCA cycle are labeled as 'TCA-only' (Figure 8). Genes involved in the TCA cycle were transcribed relatively evenly over the diel cycle, with two peaks: one in the early morning at 05:00 and the other increasing during the day from 07:00 to 15:00. At 05:00, genes encoding acetate/CoA ligase (Cagg_3789), which catalyzes the production of acetyl-CoA from acetate, also showed significantly higher relative transcription levels (Table S5). The two TCA-affiliated gene groups showed only small differences in their relative transcription patterns. After a small peak at 06:00 for all TCA-related genes, the relative transcription of the 'TCA+3-OHP' genes had already increased at 07:00, whereas the relative transcription levels of the 'TCA-only' genes were low at that time and showed a small increase later in the morning (Figure 8).

\subsection{Transcription of Oxygen Protection Genes}

Genes for two oxidative stress-protection enzymes present in the C. aggregans genome were analyzed in this study: superoxide dismutase (Cagg_2494) and two copies of a glutathione peroxidase (1: Cagg_0324 and 2: Cagg_0446). Transcripts for the enzymes showed their highest relative transcription levels during the daytime, when both $\mathrm{O}_{2}$ and light were present (Figure S3). The gene encoding superoxide dismutase, i.e., an enzyme-detoxifying reactive oxygen species, exhibited a second peak of relative transcripts in the early morning (at 05:00), when cytochrome c oxidase genes were also highly transcribed (see Section 3.4 above, "Phototrophic and Respiratory Electron Transport"). Glutathione peroxidase reduces lipid hydroperoxides to their corresponding alcohols and reduces free hydrogen peroxide to water. Significant high relative transcription levels of glutathione peroxidaseencoding genes in C. aggregans were observed at 11:00 (Figure S3), thus indicating the possible presence of not only $\mathrm{O}_{2}$ but also hydrogen peroxide.

Hydrogen peroxide is produced as a by-product in the oxidation of glycolate to glyoxylate by glycolate oxidase [66]. The encoding genes (glcDEF, Cagg_1528, Cagg_1530-1531, and Cagg_1892-1893) showed patterns similar to that of glutathione peroxidase, with the highest relative transcription levels during midday, indicating both the presence of glycolate in the mat environment and its oxidation by C. aggregans (Figure S3). The oxidation of glycolate may be linked to a photoheterotrophic metabolism, which is further supported by the high relative transcript levels for genes encoding glycoside, sugar, and amino acid transporter genes during this time under high-light conditions (Figures S4 and S5).

\section{Discussion}

\subsection{Light and $\mathrm{O}_{2}$ Dynamics Shape the Environmental Conditions for C. aggregans}

The results of microsensor analyses revealed a strong correlation between solar irradiance and the $\mathrm{O}_{2}$ concentration and penetration depth in the cyanobacterial microbial mats from Nakabusa Hot Springs (Figure 2). Since no increase in $\mathrm{O}_{2}$ concentration was observed in the bottom layer lower than $1 \mathrm{~mm}$ in depth, oxygenic cyanobacteria was supposed to be absent in the undermat as supported by the Martinez et al. [13]. The diel changes between anoxia and hyperoxic conditions driven by the oxygenic activity of cyanobacteria lead to drastic changes in the conditions for their microbial metabolism. Consequently, matinhabiting microbes may be under optimal conditions during only part of the diel cycle, and may need to endure unfavorable conditions at other times. Under such conditions, a versatile metabolism is thought to be advantageous in terms of ensuring continuous energy production under dynamic environmental conditions. In the following sections it is discussed how Chloroflexus aggregans use their metabolic flexibility to thrive in the highly variable conditions in the microbial mat over a diel cycle.

\subsection{Low Light and Low $\mathrm{O}_{2}$ Dominated the Morning Hours (07:00)}

After sunrise, although no direct sunlight hit the mats, the irradiance from diffuse light increased and stimulated cyanobacterial oxygenic photosynthesis, as indicated by the 
increasing $\mathrm{O}_{2}$ concentrations at the mat surface as well as the significant increase in the relative transcription levels of genes for protection against reactive oxygen species in C. aggregans. However, deeper mat layers were still anoxic, which in combination with low-light conditions seems to provide suitable conditions for anoxygenic photosynthesis by FAPs such as Chloroflexus spp. [67]. The increasing transcription of genes encoding housekeeping enzymes suggested increasingly active metabolism (anabolism) in C. aggregans (Figure S2). In the morning, the transcription of the phototrophy-affiliated ACIII Cp gene increased slowly and the transcription levels of genes for $\mathrm{ACIII} \mathrm{Cr}$, aurA and cytochrome $c$ oxidase decreased, which in combination indicate active phototrophy. Photoheterotrophy of C. aggregans is suggested by increases in the transcription of TCA-related genes, probably using fermentation products in the mats that accumulated during the nighttime, as reported in similar hot spring systems in Yellowstone National Park [68-72]. At the same time, photoautotrophy (and thus photomixotrophy) is indicated by the increased transcription of key 3-OHP genes, probably supported by anaplerotic carbon fixation as indicated by the increased transcription of phosphoenolpyruvate carboxylase genes (Figure 6).

Unexpectedly, neither molecular hydrogen nor sulfide seems to function as an electron donor for autotrophic growth at this time, as neither hyd nor sqr genes were highly transcribed. In contrast, a significant increase in the relative transcription levels of cox gene transcription was seen starting at 07:00, indicating that carbon monoxide is a potential electron source for photoautotrophic metabolism in the early morning, as hypothesized for the CO utilization of Roseiflexus spp. and C. aurantiacus based on the genomic analysis [11,37].

\subsection{High-Light and Super-Oxygenated Midday Hours (11:00)}

Oxygen started to accumulate in the upper mat layers from around 09:00 and with time also accumulated in the deeper mat layers. Hyperoxic $\mathrm{O}_{2}$ levels $\left(>800 \mu \mathrm{mol} \mathrm{O}_{2} \mathrm{~L}^{-1}\right)$ were observed in the uppermost mat layers and $\mathrm{O}_{2}$ penetration reached a $>2 \mathrm{~mm}$ depth under high irradiance (approx. 1000-1500 $\mu \mathrm{mol}$ photons $\mathrm{m}^{-2} \mathrm{~s}^{-1} ; 400-700 \mathrm{~nm}$ ) between 10:00 and 14:00. The relative transcription levels of genes encoding DNA gyrase, DNA/RNA polymerase and ATP synthase peaked at the same time (Figure 5 and Figure S2), indicating active growth and energy production of $C$. aggregans during midday high-light and oxic conditions.

In the laboratory, C. aggregans and other FAPs have long been known to grow chemoheterotrophically via oxic respiration under aerobic dark conditions [2]. Additionally, aerobic growth in the light has been shown for C. aurantiacus only very recently [73]. In the present study, despite the presence of $\mathrm{O}_{2}$ in the upper $2 \mathrm{~mm}$ of the mat during this period of the day, there was no indication of chemoheterotrophic growth or aerobic respiration. These results suggest the absence of both active glycolysis (as indicated by low relative transcription of the 'bacterial' type of the 6-phosphofructokinase gene) and aerobic respiration (as inferred from the transcription data of cytochrome $c$ oxidase genes and the ACIII $\mathrm{Cr}$ genes). In contrast, active phototrophy in the presence of $\mathrm{O}_{2}$ is suggested by the high relative transcription levels of genes involved in electron transport, including $\mathrm{ACIII} C \mathrm{p}$, aurB, and the TCA cycle. Structural analyses indicated that AurA and AurB in C. aurantiacus are active during phototrophic growth and chemotrophic growth, respectively [74]. In contrast, the transcription of aurB under phototrophic conditions in this study is consistent with the data obtained in a proteomic study of $C$. aurantiacus in which AurA was more abundant during chemoheterotrophic growth, while AurB was observed under photoheterotrophic conditions [45]. While the phototrophic growth under aerobic conditions correlates with earlier laboratory studies demonstrating that $\mathrm{O}_{2}$ did not inhibit energy transfer between the chlorosomes and the reaction center in C. aurantiacus [75].

However, bacteriochlorophyll biosynthesis in C. aurantiacus was long believed to be inhibited by $\mathrm{O}_{2}$, and enzymes involved in the biosynthesis were only detected or significantly increased in cultures grown under anaerobic phototrophic conditions [45]. Accordingly, metatranscriptomic studies of alkaline hot spring microbial mats in Yellowstone National Park showed that the transcripts of most of the genes involved in the biosynthesis of 
BChls in different FAPs, including Chloroflexus spp., were the most abundant at night [23]. Inhibitory effects on the biosynthesis of the photosynthetic apparatus under aerobic conditions in C. aurantiacus were also shown in the laboratory [76]. In contrast, transcription of phototrophy-related genes under aerobic light conditions were shown for C. aurantiacus only very recently [73].

In accordance with the expectation that oxygen represses the biosynthesis of phototrophic apparatus and pigments, nocturnal transcription patterns of the photosynthetic apparatus-related puf and csm genes were also observed in the present study and might be negatively correlated with the increasing $\mathrm{O}_{2}$ concentrations in the environment. In contrast, many of the bch genes were observed to be transcribed during the day, with the majority showing the highest relative transcription levels at 11:00. This correlates with a recent study of $C$. aurantiacus showing biosynthesis of $\mathrm{BChl} a$ and $c$ under anaerobic as well as aerobic conditions in the light, while being suppressed in the presence of $\mathrm{O}_{2}$ in the dark [73]. This finding supports the hypothesis that C. aggregans in Nakabusa Hot Springs cyanobacterial mats can produce BChls for phototrophic growth under aerobic conditions during the daytime.

The high relative transcription levels for glutathione peroxidase-encoding genes during the midday not only reflect high $\mathrm{O}_{2}$ levels in the environment; they might also indicate high $\mathrm{H}_{2} \mathrm{O}_{2}$ levels, since the main function of this enzyme is to reduce lipid hydroperoxides to their corresponding alcohols and to reduce free hydrogen peroxide to water $[77,78]$. Hydrogen peroxide can be formed via photochemical reactions with dissolved organic carbon in hot spring waters [79], and $\mathrm{H}_{2} \mathrm{O}_{2}$ is produced as a byproduct of the oxidation of glycolate (to glyoxylate) [66], which has been shown to be present under high-light conditions in hot spring microbial mats, presumably produced by photoinhibited cyanobacteria [69]. The presence of glycolate and its oxidation at this time of day (11:00) is further suggested by the gene transcription pattern of glycolate oxidase genes, which showed patterns similar to those of the glutathione peroxidase, with highest relative transcription levels during the midday (Figure S3). Glycolate oxidase transcription activity supports the hypothesis that Chloroflexus species photoassimilate the glycolate supplied by the cyanobacteria in such microbial mats [80]. This indicates a photoheterotrophic metabolism for C. aggregans, which is further supported by the high relative transcript levels for glycoside, sugar, and amino acid transporter genes during high-light conditions (Figures S4 and S5).

Carbon monoxide (CO) might function as an electron and/or carbon source under aerobic conditions during this time of day, as aerobic carbon monoxide dehydrogenase genes are found to peak at midday [23]. The transcription profile of carbon monoxide dehydrogenase genes was related to the transcription pattern of the phosphoenolpyruvate carboxylase gene (Figure 6), which indicates that $\mathrm{CO}$ might be converted to $\mathrm{CO}_{2}$, which then is incorporated by the phosphoenolpyruvate carboxylase-catalyzed anaplerotic reaction (phosphoenolpyruvate to oxaloacetate). In Thermomicrobium roseum, an obligately aerobic chemoheterotroph in the phylum Chloroflexota, carbon monoxide dehydrogenase is utilized to produce ATP and NADPH under aerobic conditions [81]. It is speculated that C. aggregans may use $\mathrm{CO}$ for both anaplerotic carbon fixation and supplemental energy production in the presence of $\mathrm{O}_{2}$ due to the limitation of available $\mathrm{CO}_{2}$ caused by active cyanobacterial photosynthetic carbon fixation.

Two gene clusters encoding the "respiratory" complex I (NADH:menaquinone oxidoreductase, nuo genes) are present in C. aggregans and C. aurantiacus [54,82], as well as in the red FAP species Roseiflexus castenholzii and Roseiflexus sp. RS-1 (acc. nos. CP000804 and CP000686, respectively [23,37]). To our knowledge, neither of these clusters has been affiliated with phototrophic electron transport. The different relative transcription patterns obtained in the present study might indicate that the 14-gene set is used primarily in photosynthesis and the 12-gene set is used primarily in respiratory electron transport. However, two sets of nuo operons have also been described for other, non-phototrophic bacteria such as Ignavibacterium album [83] and "Candidatus Thermonerobacter thiotrophicus" [18], which might indicate specification to different $\mathrm{O}_{2}$ levels rather than phototrophic versus 
respiratory electron transport. If true, this might indicate a potential higher $\mathrm{O}_{2}$ tolerance for the 14-gene set and a higher oxygen affinity for the 12-gene set. Because these results indicate that chemoheterotrophic, respiratory metabolism does not take place during highlight and superoxic conditions at midday, when the 14-gene set is highly transcribed, it is hypothesized that this NADH:menaquinone oxidoreductase plays a role in phototrophic electron transport, perhaps by donating electrons from NADH similar to as it has been proposed to be the case in the cyclic electron transport chain in heliobacteria [84]. However, further biochemical analyses are required to precisely determine the different functions of the two NADH: menaquinone oxidoreductases in Chloroflexus.

\subsection{Low Light and Low $\mathrm{O}_{2}$ Dominated the Afternoon Hours (15:00-16:00)}

In the afternoon, a substantial decrease in solar irradiance and $\mathrm{O}_{2}$ was observed after 14:00, as the sun set behind the surrounding mountains. Between 15:00 and 16:00, $\mathrm{O}_{2}$ was still detected only in the upper layer of the mat (Figure 2), and C. aggregans is hypothesized to experience microaerobic conditions enabling aerobic chemoheterotrophic metabolism, as indicated by the high relative transcription levels of TCA cycle, ACIII Cr, aurA, and cytochrome $c$ oxidase-encoding genes (Figures 4,5 and 8).

Simultaneously, high relative transcription levels of the gene encoding the $\mathrm{O}_{2}$-sensitive version of $\mathrm{Mg}$-protoporphyrin monomethylester cyclase, $b c h E$, indicated that part of the C. aggregans population was exposed to anoxic conditions, at least in the deeper mat layers, as supported by the microsensor data of the vertical $\mathrm{O}_{2}$ distribution in the mat (Figures 2 and 3). High relative transcription levels of genes involved in the 3-OHP bi-cycle suggest autotrophic growth, especially under anaerobic conditions, where sulfide and/or $\mathrm{H}_{2}$ is available [85]. Sulfide concentrations are expected to rise under anaerobic conditions due to biological sulfate-reduction, as was similarly shown for the bacterial community of Mushroom Spring in Yellowstone National Park [86]. The sulfide oxidation capabilities of C. aggregans in the Nakabusa mats are supported by high relative transcription levels of $s q r$ for utilization of sulfide as an electron donor [87]. At the same time, uptake hydrogenase genes are transcribed, pointing to the use of molecular hydrogen for autotrophic growth (Figure 7). However, although anoxic low-light conditions were prevalent in the deeper layers of the microbial mats for approx. $2 \mathrm{~h}$ before sunset, phototrophy does not seem to be the predominating metabolic growth mode during this time of day, as the decreasing relative transcription levels of ACIII Cp suggest. Thus, sulfide- and $\mathrm{H}_{2}$-oxidizing enzymes of $C$. aggregans may be employed for aerobic chemoautotrophic metabolism instead, or additionally for photoautotrophic metabolism at dusk, as suggested by the transcriptional peaks of ACIII Cr, aurA and cytochrome $c$ oxidase (Figures 4 and 5).

\subsection{Dark and Anoxic Nighttime Hours (17:00-19:00, 23:00, 02:10)}

After 17:00, the microbial mat community experienced dark and anoxic conditions. The low relative transcription levels for housekeeping genes such as DNA gyrase and DNA/RNA polymerases indicate low metabolic activity of $C$. aggregans during this period. The low transcription values for transporter genes support this conclusion. The electron transport gene transcripts for both phototrophy and respiration as well as for the ATPsynthase genes were low. The unidirectional glycolysis enzyme 6-phosphofructokinase gene showed significant changes towards high relative transcription levels at the beginning of the night while TCA cycle-related gene transcriptions were low, suggesting fermentative metabolism and possibly the degradation of internal glycogen storage. This has been shown for C. aurantiacus in the laboratory [56] and has been suggested for FAPs inhabiting hot spring microbial mats in Yellowstone National Park [23]. High relative transcription levels of a bi-directional hydrogenase further support the fermentative growth mode and the potential production of $\mathrm{H}_{2}$ by $C$. aggregans during the night. This is in accordance with the recent detection of $\mathrm{H}_{2}$ production under fermentative conditions (dark, anaerobic) in $C$. aggregans strain NA9-6 (unpublished data). 


\subsection{Early Morning Hours (05:00)}

Under dark, anoxic conditions in the early morning hours, an unexpected significant increase in the relative transcription of genes encoding the respiratory chain components (respiratory complexes I, II, and IV and ACIII Cr) as well as ATP-synthase was observed. It is suggested that the transcription of these genes is indicative of the occurrence of chemotrophic growth involving $\mathrm{O}_{2}$ respiration at that time of day. Although the microsensor measurements showed no presence of $\mathrm{O}_{2}$ in the mats until later in the morning, the transcription of genes encoding enzymes involved in $\mathrm{O}_{2}$ protection, such as superoxide dismutase and glutathione peroxidase, indicated a (micro)aerobic environment for C. aggregans at that time of day, and trace amounts of $\mathrm{O}_{2}$ were detected at the very surface throughout the night. As $C$. aggregans is known to have gliding motility and chemotaxis toward reduced $\mathrm{O}_{2}$ concentrations [2,88-91], it is speculated that $C$. aggregans migrates from anaerobic deeper layers to the micro-oxic surface layers in the early morning, in which a diffusive supply of $\mathrm{O}_{2}$ from the overlying water leads to microaerobic conditions during the nighttime, as has been suggested previously [23,92].

Similar to the ACIII Cr operon, the genes of the ACIII Cp operon, presumed to be involved in phototrophy, were also highly transcribed at 05:00. However, active phototrophy is ruled out due to the lack of light. Because the red filamentous anoxygenic phototrophic members of Chloroflexota-i.e., Roseiflexus spp.-contain only one copy of Cp-like ACIII genes, which are predicted to work under both phototrophic and chemotrophic conditions [23], the Cp-related genes in C. aggregans might also function under chemotrophic growth in the mats.

A capacity for chemoautotrophic growth was very recently observed in Chloroflexus spp. isolates obtained from Nakabusa Hot Springs microbial mats [8]. The high relative transcription levels of hyd uptake hydrogenase and Ni-transporter genes further suggest the use of $\mathrm{H}_{2}$ as an electron donor for the aerobic chemoautotrophic growth in the microoxic surface layers of the cyanobacterial mats around 05:00. Additionally, the high transcription levels of genes for the TCA cycle and acetate/CoA ligase-the latter of which catalyzes the production of acetyl-CoA from acetate-indicate that acetate, supplied mainly from the fermentation of co-existing microbes as shown in similar mats in Yellowstone National Park, might be taken up at this time of day $[22,68,93,94]$ (Table S5). This points to the possibility of an assimilation of acetate in addition to the purely autotrophic metabolism, suggesting the chemomixotrophic lifestyle of $C$. aggregans during predawn.

\section{Conclusions}

This study suggests that $C$. aggregans uses its metabolic flexibility and capability for both phototrophic and chemotrophic growth to optimize its performance under the varying environmental conditions in its natural habitat, the microbial mat community at Nakabusa Hot Springs. The main ATP-generating and thus metabolically most-active times are not only the high-light hours around midday (phototrophy), but-most notablyalso the early morning hours around 05:00, when the cells are hypothesized to conduct chemomixotrophic growth (Figure 9).

Genes for the biosynthesis of the photosynthetic apparatus are predominantly transcribed during the night; however, photosynthesis is active during the light hours in the morning, midday and afternoon. Under low $\mathrm{O}_{2}$ concentrations in the dim morning light $\left(\leq 100 \mu \mathrm{mol}\right.$ photons $\mathrm{m}^{-2} \mathrm{~s}^{-1}$ ), photoauto/mixotrophic metabolism potentially using CO as an electron donor is suggested to be the major energy source for C. aggregans in the cyanobacteria-dominated mats. Later on, under midday high-light conditions, intense oxygenic photosynthesis by cyanobacteria renders the upper millimeters of the microbial mat highly oxic. However, $\mathrm{O}_{2}$ respiration in $\mathrm{C}$. aggregans does not seem to take place under these conditions. Instead, photoheterotrophic growth (and the assimilation of glycolate) is most likely the dominant lifestyle, supplemented with a certain degree of anaplerotic $\mathrm{CO}_{2}$ fixation. In the afternoon, under anaerobic light conditions, photoautotrophic or photomixotrophic growth with sulfide and/or $\mathrm{H}_{2}$ as the electron donor takes place in the 
deeper mat layers, and aerobic respiration and chemoheterotrophic growth are hypothesized for the cells in the upper layers. At nighttime, chemoheterotrophic fermentative growth and the production of $\mathrm{H}_{2}$ may take place. In the late-night/early morning hours, at around 05:00, Chloroflexus migrates to the mat surface and undergoes mixotrophic growth with $\mathrm{H}_{2}$ and $\mathrm{O}_{2}$ prior to sunrise, after which $C$. aggregans switches back to phototrophy.

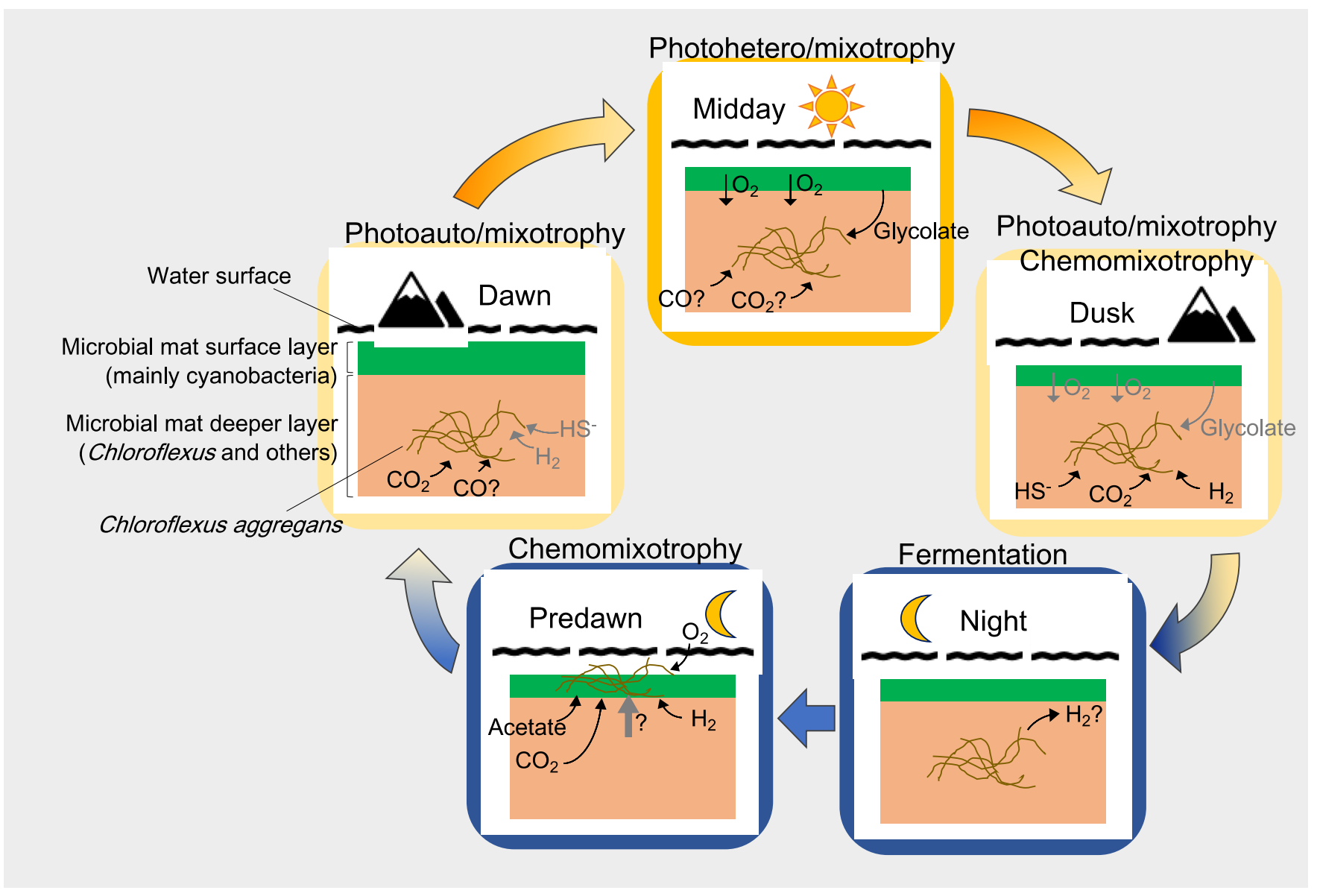

Figure 9. Proposed diel growth modes of C. aggregans (indicated by brown filaments) in cyanobacterial mats based on in situ metatranscriptomic and microsensor analyses in the cyanobacterial mats of Nakabusa Hot Springs. The green area represents the green upper layer containing oxygenic phototrophs (i.e., cyanobacteria), while the orange area corresponds to the orange colored undermat. The black curvy line indicated the overflowing water surface.

Supplementary Materials: The following are available online at https://www.mdpi.com/2076 -2607/9/3/652/s1, Figure S1: Relative transcription levels of paralogous respiratory complex I; Figure S2: Relative transcription levels of housekeeping genes; Figure S3: Relative transcription levels of genes related to oxidative stresses; Figure S4: Relative transcription levels of amino acid and oligopeptide transporter genes; Figure S5: Relative transcription levels of glycoside and sugar transporter genes; Table S1: Transcriptomic profiles and differentially transcribed genes; Table S2: Differential transcription analyses of genes involved in energy metabolisms of C. aggregans; Table S3: Summary of differentially transcribed genes; Table S4: Transcription patterns of $b c h$ genes; Table S5: Transcription patterns of genes involved in energy metabolisms of C. aggregans.

Author Contributions: Conceptualization, S.K. and V.T.; Transcriptomic data analysis, S.K.; RNA extraction, J.N.M.; Microsensor measurements and analysis, M.L., E.T., and M.K.; Sample collection, J.N.M., M.T., A.N., and V.T.; Writing-original draft preparation, S.K. and V.T.; Writing-review and editing, S.K., V.T., M.T., M.K., M.L., E.T., S.H. (Shin Haruta), A.N., and J.N.M.; Supervision, V.T. and S.H. (Shin Haruta); Funding acquisition, S.H. (Satoshi Hanada), M.K., and A.N. All authors have read and agreed to the published version of the manuscript. 
Funding: This study was supported by the Institute for Fermentation, Osaka (IFO) to S.H. (Satoshi Hanada), grants from the Independent Research Fund Denmark (DFF-1323-00065B; DFF-8021-00308B) to M.K., and the fund from international practice course of Tokyo Metropolitan University to A.N.

Institutional Review Board Statement: Not applicable.

Informed Consent Statement: Not applicable.

Data Availability Statement: The sequence collected in this study is available under NCBI BioProject accession number PRJNA715822.

Acknowledgments: The authors would like to thank the owner of Nakabusa Hot Spring (Takahito Momose) for the permission to collect samples from the hot spring.

Conflicts of Interest: The authors declare no conflict of interest.

\section{References}

1. Pierson, B.K.; Castenholz, R.W. A phototrophic gliding filamentous bacterium of hot springs, Chloroflexus aurantiacus, gen. and sp. nov. Arch. Microbiol. 1974, 100, 5-24. [CrossRef]

2. Hanada, S.; Hiraishi, A.; Shimada, K.; Matsuura, K. Chloroflexus aggregans sp. nov., a filamentous phototrophic bacterium which forms dense cell aggregates by active gliding movement. Int. J. Syst. Bacteriol. 1995, 45, 676-681. [CrossRef] [PubMed]

3. Gaisin, V.A.; Kalashnikov, A.M.; Grouzdev, D.S.; Sukhacheva, M.V.; Kuznetsov, B.B.; Gorlenko, V.M. Chloroflexus islandicus sp. nov., a thermophilic filamentous anoxygenic phototrophic bacterium from a geyser. Int. J. Syst. Evol. Microbiol. 2017, 67, 1381-1386. [CrossRef] [PubMed]

4. Madigan, M.T.; Petersen, S.R.; Brock, T.D. Nutritional studies on Chloroflexus, a filamentous photosynthetic, gliding bacterium. Arch. Microbiol. 1974, 100, 97-103. [CrossRef]

5. Sirevag, R.; Castenholz, R. Aspects of carbon metabolism in Chloroflexus. Arch. Microbiol. 1979, 120, 151-153. [CrossRef]

6. Holo, H.; Sirevag, R. Autotrophic growth and $\mathrm{CO}_{2}$ fixation of Chloroflexus aurantiacus. Arch. Microbiol. 1986, 145, 173-180. [CrossRef]

7. Thiel, V.; Hamilton, T.L.; Tomsho, L.P.; Burhans, R.; Gay, S.E.; Schuster, S.C.; Ward, D.M.; Bryant, D.A. Draft genome sequence of a sulfide-oxidizing, autotrophic filamentous anoxygenic phototrophic bacterium, Chloroflexus sp. strain MS-G (Chloroflexi). Genome Announc. 2014, 2, 9-10. [CrossRef] [PubMed]

8. Kawai, S.; Nishihara, A.; Matsuura, K.; Haruta, S. Hydrogen-dependent autotrophic growth in phototrophic and chemolithotrophic cultures of thermophilic bacteria, Chloroflexus aggregans and Chloroflexus aurantiacus, isolated from Nakabusa hot springs. FEMS Microbiol. Lett. 2019, 366, 1-6. [CrossRef]

9. Kawai, S.; Kamiya, N.; Matsuura, K.; Haruta, S. Symbiotic growth of a thermophilic sulfide-oxidizing photoautotroph and an elemental sulfur-disproportionating chemolithoautotroph and cooperative dissimilatory oxidation of sulfide to sulfate. Front. Microbiol. 2019, 10, 1-8. [CrossRef] [PubMed]

10. Kanno, N.; Haruta, S.; Hanada, S. Sulfide-dependent photoautotrophy in the filamentous anoxygenic phototrophic bacterium, Chloroflexus aggregans. Microbes Environ. 2019, 34, 304-309. [CrossRef] [PubMed]

11. Tang, K.H.; Barry, K.; Chertkov, O.; Dalin, E.; Han, C.S.; Hauser, L.J.; Honchak, B.M.; Karbach, L.E.; Land, M.L.; Lapidus, A.; et al. Complete genome sequence of the filamentous anoxygenic phototrophic bacterium Chloroflexus aurantiacus. BMC Genom. 2011, 12, 1-21. [CrossRef] [PubMed]

12. Kondratieva, E.N.; Ivanovsky, R.N.; Krasilnikova, E.N. Carbon metabolism in Chloroflexus aurantiacus. FEMS Microbiol. Lett. 1992, 100, 269-271. [CrossRef]

13. Martinez, J.N.; Nishihara, A.; Lichtenberg, M.; Trampe, E.; Kawai, S.; Tank, M.; Kühl, M.; Hanada, S.; Thiel, V. Vertical distribution and diversity of phototrophic bacteria within a hot spring microbial mat (Nakabusa hot springs, Japan). Microbes Environ. 2019, 34, 374-387. [CrossRef]

14. Everroad, R.C.; Otaki, H.; Matsuura, K.; Haruta, S. Diversification of bacterial community composition along a temperature gradient at a thermal spring. Microbes Environ. 2012, 27, 374-381. [CrossRef] [PubMed]

15. Kubo, K.; Knittel, K.; Amann, R.; Fukui, M.; Matsuura, K. Sulfur-metabolizing bacterial populations in microbial mats of the Nakabusa hot spring, Japan. Syst. Appl. Microbiol. 2011, 34, 293-302. [CrossRef] [PubMed]

16. Otaki, H.; Everroad, R.C.; Matsuura, K.; Haruta, S. Production and consumption of hydrogen in hot spring microbial mats dominated by a filamentous anoxygenic photosynthetic bacterium. Microbes Environ. 2012, 27, 293-299. [CrossRef] [PubMed]

17. Tamazawa, S.; Yamamoto, K.; Takasaki, K.; Mitani, Y.; Hanada, S.; Kamagata, Y.; Tamaki, H. In situ gene expression responsible for sulfide oxidation and $\mathrm{CO}_{2}$ fixation of an uncultured large sausage-shaped Aquificae bacterium in a sulfidic hot spring. Microbes Environ. 2016, 31, 194-198. [CrossRef] [PubMed]

18. Thiel, V.; Garcia Costas, A.M.; Fortney, N.W.; Martinez, J.N.; Tank, M.; Roden, E.E.; Boyd, E.S.; Ward, D.M.; Hanada, S.; Bryant, D.A. "Candidatus thermonerobacter thiotrophicus," a non-phototrophic member of the Bacteroidetes/Chlorobi with dissimilatory sulfur metabolism in hot spring mat communities. Front. Microbiol. 2019, 10, 3159. [CrossRef] [PubMed] 
19. Nishihara, A.; Matsuura, K.; Tank, M.; McGlynn, S.E.; Thiel, V.; Haruta, S. Nitrogenase activity in thermophilic chemolithoautotrophic bacteria in the phylum Aquificae isolated under nitrogen-fixing conditions from Nakabusa hot springs. Microbes Environ. 2018, 33, 394-401. [CrossRef] [PubMed]

20. Nishihara, A.; Haruta, S.; McGlynn, S.E.; Thiel, V.; Matsuura, K. Nitrogen fixation in thermophilic chemosynthetic microbial communities depending on hydrogen, sulfate, and carbon dioxide. Microbes Environ. 2018, 33, 10-18. [CrossRef]

21. Nishihara, A.; Thiel, V.; Matsuura, K.; McGlynn, S.E.; Haruta, S. Phylogenetic diversity of nitrogenase reductase genes and possible nitrogen-fixing bacteria in thermophilic chemosynthetic microbial communities in Nakabusa hot springs. Microbes Environ. 2018, 33, 357-365. [CrossRef] [PubMed]

22. van der Meer, M.T.J.; Schouten, S.; Bateson, M.M.; Nübel, U.; Wieland, A.; Kühl, M.; De Leeuw, J.W.; Damsté, J.S.S.; Ward, D.M. Diel variations in carbon metabolism by green nonsulfur-like bacteria in alkaline siliceous hot spring microbial mats from Yellowstone National Park. Appl. Environ. Microbiol. 2005, 71, 3978-3986. [CrossRef] [PubMed]

23. Klatt, C.G.; Liu, Z.; Ludwig, M.; Kühl, M.; Jensen, S.I.; Bryant, D.A.; Ward, D.M. Temporal metatranscriptomic patterning in phototrophic Chloroflexi inhabiting a microbial mat in a geothermal spring. ISME J. 2013, 7, 1775-1789. [CrossRef] [PubMed]

24. Thiel, V.; Wood, J.M.; Olsen, M.T.; Tank, M.; Klatt, C.G.; Ward, D.M.; Bryant, D.A. The dark side of the mushroom spring microbial mat: Life in the shadow of chlorophototrophs. I. Microbial diversity based on 16S rRNA gene amplicons and metagenomic sequencing. Front. Microbiol. 2016, 7, 1-25. [CrossRef]

25. Hiroyuki, K.; Mori, K.; Nashimoto, H.; Hanada, S.; Kato, K. In situ biomass production of a hot spring sulfur-turf microbial mat. Microbes Environ. 2010, 25, 140-143.

26. Kato, K.; Kobayashi, T.; Yamamoto, H.; Nakagawa, T.; Maki, Y.; Hoaki, T. Microbial mat boundaries between chemolithotrophs and phototrophs in geothermal hot spring effluents. Geomicrobiol. J. 2004, 21, 91-98. [CrossRef]

27. Nakagawa, T.; Fukui, M. Phylogenetic characterization of microbial mats and streamers from a Japanese alkaline hot spring with a thermal gradient. J. Gen. Appl. Microbiol. 2002, 48, 211-222. [CrossRef]

28. Andrews S FastQC. A Quality Control Tool for High Throughput Sequence Data. Available online: http://www.bioinformatics. babraham.ac.uk/projects/fastqc/ (accessed on 29 March 2018).

29. Martin, M. Cutadapt removes adapter sequences from high-throughput sequencing reads. EMBnet. J. 2011, 17, 10-12. [CrossRef]

30. Langmead, B.; Salzberg, S. Fast gapped-read alignment with Bowtie 2. Nat. Methods 2013, 9, 357-359. [CrossRef] [PubMed]

31. Magoc, T.; Wood, D.; Salzberg, S.L. EDGE-pro: Eestimated Degree of Gene Expression in prokaryotic genomes. Evol. Bioinform. 2013, 9, 127-136. [CrossRef] [PubMed]

32. Robinson, M.D.; McCarthy, D.J.; Smyth, G.K. edgeR: A Bioconductor package for differential expression analysis of digital gene expression data. Bioinformatics 2009, 26, 139-140. [CrossRef]

33. Liu, Z.; Koid, A.E.; Terrado, R.; Campbell, V.; Caron, D.A.; Heidelberg, K.B. Changes in gene expression of Prymnesium parvum induced by nitrogen and phosphorus limitation. Front. Microbiol. 2015, 6, 1-13. [CrossRef] [PubMed]

34. Tang, K.H.; Wen, J.; Li, X.; Blankenship, R.E. Role of the AcsF protein in Chloroflexus aurantiacus. J. Bacteriol. 2009, 191, 3580-3587. [CrossRef]

35. Frigaard, N.U.; Maqueo Chew, A.G.; Maresca, J.A.; Bryant, D.A. Bacteriochlorophyll biosynthesis in green bacteria. Chlorophylls Bacteriochlorophylls 2007, 25, 201-221.

36. Chew, A.G.M.; Bryant, D.A. Chlorophyll biosynthesis in bacteria: The origins of structural and functional diversity. Annu. Rev. Microbiol. 2007, 61, 113-129. [CrossRef] [PubMed]

37. van der Meer, M.T.J.; Klatt, C.G.; Wood, J.; Bryant, D.A.; Bateson, M.M.; Lammerts, L.; Schouten, S.; Sinninghe Damste, J.S.; Madigan, M.T.; Ward, D.M. Cultivation and genomic, nutritional, and lipid biomarker characterization of Roseiflexus strains closely related to predominant in situ populations inhabiting Yellowstone hot spring microbial mats. J. Bacteriol. 2010, 192, 3033-3042. [CrossRef] [PubMed]

38. Garcia Costas, A.M.; Tsukatani, Y.; Rijpstra, W.I.C.; Schouten, S.; Welander, P.V.; Summons, R.E.; Bryant, D.A. Identification of the bacteriochlorophylls, carotenoids, quinones, lipids, and hopanoids of "candidatus chloracidobacterium thermophilum". J. Bacteriol. 2012, 194, 1158-1168. [CrossRef] [PubMed]

39. Yanyushin, M.F.; Del Rosario, M.C.; Brune, D.C.; Blankenship, R.E. New class of bacterial membrane oxidoreductases. Biochemistry 2005, 44, 10037-10045. [CrossRef]

40. Gao, X.; Xin, Y.; Blankenship, R.E. Enzymatic activity of the alternative complex III as a menaquinol:auracyanin oxidoreductase in the electron transfer chain of Chloroflexus aurantiacus. FEBS Lett. 2009, 583, 3275-3279. [CrossRef]

41. Gao, X.; Xin, Y.; Bell, P.D.; Wen, J.; Blankenship, R.E. Structural analysis of alternative complex III in the photosynthetic electron transfer chain of Chloroflexus aurantiacus. Biochemistry 2010, 49, 6670-6679. [CrossRef]

42. McManus, J.D.; Brune, D.C.; Han, J.; Sanders-Loehr, J.; Meyer, T.E.; Cusanovich, M.A.; Tollin, G.; Blankenship, R.E. Isolation, characterization, and amino acid sequences of auracyanins, blue copper proteins from the green photosynthetic bacterium Chloroflexus aurantiacus. J. Biol. Chem. 1992, 267, 6531-6540. [CrossRef]

43. Van Driessche, G.; Hu, W.; Van De Werken, G.; Selvaraj, F.; Mcmanus, J.D.; Blankenship, R.E.; Van Beeumen, J.J. Auracyanin a from the thermophilic green gliding photosynthetic bacterium Chloroflexus aurantiacus represents an unusual class of small blue copper proteins. Protein Sci. 1999, 8, 947-957. [CrossRef] 
44. Tsukatani, Y.; Nakayama, N.; Shimada, K.; Mino, H.; Itoh, S.; Matsuura, K.; Hanada, S.; Nagashima, K.V.P. Characterization of a blue-copper protein, auracyanin, of the filamentous anoxygenic phototrophic bacterium Roseiflexus castenholzii. Arch. Biochem. Biophys. 2009, 490, 57-62. [CrossRef] [PubMed]

45. Cao, L.; Bryant, D.A.; Schepmoes, A.A.; Vogl, K.; Smith, R.D.; Lipton, M.S.; Callister, S.J. Comparison of Chloroflexus aurantiacus strain J-10-fl proteomes of cells grown chemoheterotrophically and photoheterotrophically. Photosynth. Res. 2012, 110, 153-168. [CrossRef]

46. Xin, Y.; Lu, Y.K.; Fromme, R.; Fromme, P.; Blankenship, R.E. Purification, characterization and crystallization of menaquinol:fumarate oxidoreductase from the green filamentous photosynthetic bacterium Chloroflexus aurantiacus. Biochim. Biophys. Acta Bioenerg. 2009, 1787, 86-96. [CrossRef] [PubMed]

47. Schmidt, K. A comparative study on the composition of chlorosomes (Chlorobium vesicles) and cytoplasmic membranes from Chloroflexus aurantiacus strain Ok-70-fl and Chlorobium limicola f. thiosulfatophilum strain 6230. Arch. Microbiol. 1980, 124, $21-31$. [CrossRef]

48. Yanyushin, M.F. Subunit structure of ATP synthase from Chloroflexus aurantiacus. FEBS Lett. 1993, 335, 85-88. [CrossRef]

49. Chadwick, G.L.; Hemp, J.; Fischer, W.W.; Orphan, V.J. Convergent evolution of unusual complex I homologs with increased proton pumping capacity: Energetic and ecological implications. ISME J. 2018, 12, 2668-2680. [CrossRef] [PubMed]

50. Hägerhäll, C. Succinate: Quinone oxidoreductases. Biochim. Biophys. Acta Bioenerg. 1997, 1320, 107-141. [CrossRef]

51. Lemos, R.S.; Fernandes, A.S.; Pereira, M.M.; Gomes, C.M.; Teixeira, M. Quinol:fumarate oxidoreductases and succinate:quinone oxidoreductases: Phylogenetic relationships, metal centres and membrane attachment. Biochim. Biophys. Acta Bioenerg. 2002, 1553, 158-170. [CrossRef]

52. Eisenreich, W.; Strauss, G.; Werz, U.; Fuchs, G.; Bacher, A. Retrobiosynthetic analysis of carbon fixation in the phototrophic eubacterium Chloroflexus aurantiacus. Eur. J. Biochem. 1993, 215, 619-632. [CrossRef] [PubMed]

53. Strauss, G.; Fuchs, G. Enzymes of a novel autotrophic $\mathrm{CO}_{2}$ fixation pathway in the phototrophic bacterium Chloroflexus aurantiacus, the 3- hydroxypropionate cycle. Eur. J. Biochem. 1993, 215, 633-643. [CrossRef] [PubMed]

54. Klatt, C.G.; Bryant, D.A.; Ward, D.M. Comparative genomics provides evidence for the 3-hydroxypropionate autotrophic pathway in filamentous anoxygenic phototrophic bacteria and in hot spring microbial mats. Environ. Microbiol. 2007, 9, 2067-2078. [CrossRef] [PubMed]

55. Herter, S.; Fuchs, G.; Bacher, A.; Eisenreich, W. A bicyclic autotrophic $\mathrm{CO}_{2}$ fixation pathway in Chloroflexus aurantiacus. J. Biol. Chem. 2002, 277, 20277-20283. [CrossRef]

56. Zarzycki, J.; Fuchs, G. Coassimilation of organic substrates via the autotrophic 3-hydroxypropionate bi-cycle in Chloroflexus aurantiacus. Appl. Environ. Microbiol. 2011, 77, 6181-6188. [CrossRef] [PubMed]

57. van der Meer, M.T.J.; Schouten, S.; De Leeuw, J.W.; Ward, D.M. Autotrophy of green non-sulphur bacteria in hot spring microbial mats: Biological explanations for isotopically heavy organic carbon in the geological record. Environ. Microbiol. 2000, 2, 428-435. [CrossRef]

58. Dunn, M.F. Anaplerotic function of phosphoenolpyruvate carboxylase in Bradyrhizobium japonicum USDA110. Curr. Microbiol. 2011, 62, 1782-1788. [CrossRef]

59. Dunn, M.F. Tricarboxylic acid cycle and anaplerotic enzymes in rhizobia. FEMS Microbiol. Rev. 1998, 22, 105-123. [CrossRef] [PubMed]

60. Vignais, P.M.; Billoud, B.; Meyer, J. Classifcation and phylogeny of hydrogenases. FEMS Microbiol. Rev. 2001, 25, 455-501. [CrossRef]

61. Vignais, P.M.; Billoud, B. Occurrence, classification, and biological function of hydrogenases: An overview. Chem. Rev. 2007, 107, 4206-4272. [CrossRef] [PubMed]

62. Gregersen, L.H.; Bryant, D.A.; Frigaard, N.U. Mechanisms and evolution of oxidative sulfur metabolism in green sulfur bacteria. Front. Microbiol. 2011, 2, 1-14. [CrossRef]

63. Friedrich, C.G.; Bardischewsky, F.; Rother, D.; Quentmeier, A.; Fischer, J. Prokaryotic sulfur oxidation. Curr. Opin. Microbiol. 2005, 8, 253-259. [CrossRef]

64. Lu, S.; Wang, J.; Chitsaz, F.; Derbyshire, M.K.; Geer, R.C.; Gonzales, N.R.; Gwadz, M.; Hurwitz, D.I.; Marchler, G.H.; Song, J.S.; et al. CDD/SPARCLE: The conserved domain database in 2020. Nucleic Acids Res. 2020, 48, D265-D268. [CrossRef] [PubMed]

65. Hügler, M.; Sievert, S.M. Beyond the calvin cycle: Autotrophic carbon fixation in the ocean. Ann. Rev. Mar. Sci. 2011, 3, 261-289. [CrossRef] [PubMed]

66. Zimmermann, P.; Zentgraf, U. The correlation between oxidative stress and leaf senescence during plant development. Cell. Mol. Biol. Lett. 2005, 10, 515-534.

67. Oostergetel, G.T.; van Amerongen, H.; Boekema, E.J. The chlorosome: A prototype for efficient light harvesting in photosynthesis. Photosynth. Res. 2010, 104, 245-255. [CrossRef]

68. van der Meer, M.T.J.; Schouten, S.; Damsté, J.S.S.; Ward, D.M. Impact of carbon metabolism on ${ }^{13}$ C signatures of cyanobacteria and green non-sulfur-like bacteria inhabiting a microbial mat from an alkaline siliceous hot spring in Yellowstone National Park (USA). Environ. Microbiol. 2007, 9, 482-491. [CrossRef] [PubMed]

69. Kim, Y.M.; Nowack, S.; Olsen, M.; Becraft, E.D.; Wood, J.M.; Thiel, V.; Klapper, I.; Kühl, M.; Fredrickson, J.K.; Bryant, D.A.; et al. Diel metabolomics analysis of a hot spring chlorophototrophic microbial mat leads to new hypotheses of community member metabolisms. Front. Microbiol. 2015, 6, 209. [CrossRef] [PubMed] 
70. Bhaya, D.; Grossman, A.R.; Steunou, A.S.; Khuri, N.; Cohan, F.M.; Hamamura, N.; Melendrez, M.C.; Bateson, M.M.; Ward, D.M.; Heidelberg, J.F. Population level functional diversity in a microbial community revealed by comparative genomic and metagenomic analyses. ISME J. 2007, 1, 703-713. [CrossRef]

71. Steunou, A.S.; Jensen, S.I.; Brecht, E.; Becraft, E.D.; Bateson, M.M.; Kilian, O.; Bhaya, D.; Ward, D.M.; Peters, J.W.; Grossman, A.R.; et al. Regulation of nif gene expression and the energetics of $\mathrm{N}_{2}$ fixation over the diel cycle in a hot spring microbial mat. ISME J. 2008, 2, 364-378. [CrossRef] [PubMed]

72. Steunou, A.S.; Bhaya, D.; Bateson, M.M.; Melendrez, M.C.; Ward, D.M.; Brecht, E.; Peters, J.W.; Kühl, M.; Grossman, A.R. In situ analysis of nitrogen fixation and metabolic switching in unicellular thermophilic cyanobacteria inhabiting hot spring microbial mats. Proc. Natl. Acad. Sci. USA 2006, 103, 2398-2403. [CrossRef] [PubMed]

73. Izaki, K.; Haruta, S. Aerobic production of bacteriochlorophylls in the filamentous anoxygenic photosynthetic bacterium, Chloroflexus aurantiacus in the light. Microbes Environ. 2020, 35, 1-5. [CrossRef]

74. Lee, M.; Del Rosario, M.C.; Harris, H.H.; Blankenship, R.E.; Guss, J.M.; Freeman, H.C. The crystal structure of auracyanin A at $1.85 \AA$ resolution: The structures and functions of auracyanins A and B, two almost identical "blue" copper proteins, in the photosynthetic bacterium Chloroflexus aurantiacus. J. Biol. Inorg. Chem. 2009, 14, 329-345. [CrossRef]

75. Frigaard, N.U.; Tokita, S.; Matsuura, K. Exogenous quinones inhibit photosynthetic electron transfer in Chloroflexus aurantiacus by specific quenching of the excited bacteriochlorophyll $c$ antenna. Biochim. Biophys. Acta Bioenerg. 1999, 1413, 108-116. [CrossRef]

76. Oelze, J. Light and oxygen regulation of the synthesis of bacteriochlorophylls $a$ and $c$ in Chloroflexus aurantiacus. J. Bacteriol. 1992, 174, 5021-5026. [CrossRef]

77. Mishara, S.; Imlay, J. Why do bacteria use so many enzymes to scavenge hydrogen peroxide? Arch. Biochem. Biophys. 2012, 525, 145-160. [CrossRef] [PubMed]

78. Cabiscol, E.; Tamarit, J.; Ros, J. Oxidative stress in bacteria and protein damage by reactive oxygen species. Int. Microbiol. 2000, 3, 3-8. [PubMed]

79. Wilson, C.L.; Hinman, N.W.; Cooper, W.J.; Brown, C.F. Hydrogen peroxide cycling in surface geothermal waters of yellowstone national park. Environ. Sci. Technol. 2000, 34, 2655-2662. [CrossRef]

80. Bateson, M.M.; Ward, D.M. Photoexcretion and fate of glycolate in a hot spring cyanobacterial mat. Appl. Environ. Microbiol. 1988, 54, 1738-1743. [CrossRef] [PubMed]

81. Wu, D.; Raymond, J.; Wu, M.; Chatterji, S.; Ren, Q.; Graham, J.E.; Bryant, D.A.; Robb, F.; Colman, A.; Tallon, L.J.; et al. Complete genome sequence of the aerobic CO-oxidizing thermophile Thermomicrobium roseum. PLoS ONE 2009, 4, e4207. [CrossRef] [PubMed]

82. Zannoni, D.; Fuller, R.C. Functional and spectral characterization of the respiratory chain of Chloroflexus aurantiacus grown in the dark under oxygen-saturated conditions. Arch. Microbiol. 1988, 150, 368-373. [CrossRef]

83. Liu, Z.; Frigaard, N.U.; Vogl, K.; Iino, T.; Ohkuma, M.; Overmann, J.; Bryant, D.A. Complete genome of Ignavibacterium album, a metabolically versatile, flagellated, facultative anaerobe from the phylum Chlorobi. Front. Microbiol. 2012, 3, 1-15. [CrossRef]

84. Kramer, D.M.; Schoepp, B.; Liebl, U.; Nitschke, W. Cyclic electron transfer in Heliobacillus mobilis involving a menaquinol-oxidizing cytochrome $b c$ complex and an RCI-type reaction center. Biochemistry 1997, 36, 4203-4211. [CrossRef] [PubMed]

85. Revsbech, N.P.; Trampe, E.; Lichtenberg, M.; Ward, D.M.; Kühl, M. In situ hydrogen dynamics in a hot spring microbial mat during a diel cycle. Appl. Environ. Microbiol. 2016, 82, 4209-4217. [CrossRef] [PubMed]

86. Dillon, J.G.; Fishbain, S.; Miller, S.R.; Bebout, B.M.; Habicht, K.S.; Webb, S.M.; Stahl, D.A. High rates of sulfate reduction in a low-sulfate hot spring microbial mat are driven by a low level of diversity of sulfate-respiring microorganisms. Appl. Environ. Microbiol. 2007, 73, 5218-5226. [CrossRef] [PubMed]

87. Marcia, M.; Ermler, U.; Peng, G.; Michel, H. The structure of Aquifex aeolicus sulfide:quinone oxidoreductase, a basis to understand sulfide detoxification and respiration. Proc. Natl. Acad. Sci. USA 2009, 106, 9625-9630. [CrossRef] [PubMed]

88. Morohoshi, S.; Matsuura, K.; Haruta, S. Secreted protease mediates interspecies interaction and promotes cell aggregation of the photosynthetic bacterium Chloroflexus aggregans. FEMS Microbiol. Lett. 2015, 362, 1-5. [CrossRef]

89. Hanada, S.; Shimada, K.; Matsuura, K. Active and energy-dependent rapid formation of cell aggregates in the thermophilic photosynthetic bacterium Chloroflexus aggregans. FEMS Microbiol. Lett. 2002, 208, 275-279. [CrossRef] [PubMed]

90. Fukushima, S. Analysis of gliding motility of the filamentous bacterium Chloroflexus aggregans. Ph.D. Thesis, Tokyo Metropolitan University, Tokyo, Japan, 2016.

91. Fukushima, S.I.; Morohoshi, S.; Hanada, S.; Matsuura, K.; Haruta, S. Gliding motility driven by individual cell-surface movements in a multicellular filamentous bacterium Chloroflexus aggregans. FEMS Microbiol. Lett. 2016, 363, 1-5. [CrossRef] [PubMed]

92. Doemel, W.N.; Brock, T.D. Structure, growth, and decomposition of laminated algal-bacterial mats in alkaline hot springs. Appl. Environ. Microbiol. 1977, 34, 433-452. [CrossRef] [PubMed]

93. Anderson, K.L.; Tayne, T.A.; Ward, D.M. Formation and fate of fermentation products in hot spring cyanobacterial mats. Appl. Environ. Microbiol. 1987, 53, 2343-2352. [CrossRef] [PubMed]

94. Nold, S.C.; Ward, D.M. Photosynthate partitioning and fermentation in hot spring microbial mat communities. Appl. Environ. Microbiol. 1996, 62, 4598-4607. [CrossRef] [PubMed] 